\title{
The Role of Polygonal Eyewalls in Rapid Intensification of Typhoon Megi (2010)
}

\author{
JAE-DEOK LEE AND CHUN-CHIEH Wu \\ Department of Atmospheric Sciences, National Taiwan University, Taipei, Taiwan
}

(Manuscript received 29 March 2018, in final form 7 September 2018)

\begin{abstract}
High-resolution numerical experiments for Typhoon Megi (2010) in the western North Pacific are conducted using the Advanced Research version of the Weather Research and Forecasting (WRF) Model to understand the mechanisms of rapid intensification (RI). With a dynamically initialized vortex, sensitivity experiments are carried out focusing on the planetary boundary layer (PBL) and the following microphysics schemes: WRF single-moment 6-class (WSM6) and WRF double-moment 6-class (WDM6) microphysics with Yonsei University, Mellor-Yamada-Janjić (MYJ), and Mellor-Yamada-Nakanishi-Niino (MYNN) 2.5-level (MN2.5) and 3.0-level (MN3) PBL schemes. The largest differences are found between WSM6-MN3 and WDM6-MN3, and we therefore examine RI mechanisms based on the results of these experiments. Prior to RI, WDM6-MN3 shows a drier environment and stronger downdrafts in the lower troposphere than in WSM6-MN3. As a result, during the RI period, WSM6-MN3 (WDM6-MN3) significantly intensifies with the minimum sea level pressure decreasing by $51(29) \mathrm{hPa}$ and the maximum surface wind increasing by $28(12) \mathrm{m} \mathrm{s}^{-1}$ in $24 \mathrm{~h}$. In both experiments, the maximum values of surface heat fluxes, potential vorticity (PV), radial absolute angular momentum advection, inertial stability, supergradient wind, and convective bursts inside the radius of maximum winds are frequently observed at each vertex of polygonal eyewalls in the lower troposphere. In particular, WSM6-MN3 exhibits more convective cells inside the inner-core region, a more persistent and thicker polygonal eyewall in the lower troposphere, and a more robust vertical structure of hydrometeors and vertical velocity than WDM6-MN3. This study suggests that within the inner-core region, polygonal eyewalls like WSM6-MN3 provide favorable conditions for RI.
\end{abstract}

\section{Introduction}

An intense tropical cyclone (TC) can usually be characterized by a distinct eye and eyewall structure with strong vortical flows and robust convection near the eyewall. Intense TCs generally bring many casualties as well as a huge loss of property when making landfall. Fortunately, based on the considerable observation data availability, sophisticated numerical models, and theoretical work, TC track forecasts have been substantially improved over the past few decades (Goerss et al. 2004; DeMaria et al. 2014). However, progress in TC-intensity forecasting remains slow, partly because of the lack of understanding of highly nonlinear interactions within the eyewall (Wang and Wu 2004).

In general, large-scale environmental predictors such as vertical wind shear (VWS), upper-tropospheric divergence, sea surface temperature (SST), ocean heat content $(\mathrm{OHC})$, and relative humidity determine whether

Corresponding author: Dr. Chun-Chieh Wu, cwu@typhoon.as. ntu.edu.tw conditions are favorable for TC intensification (Kaplan and DeMaria 2003; Kaplan et al. 2010). Under favorable conditions, TCs can intensify through interactions of microphysical, cumulus, and planetary boundary layer (PBL) processes by a series of nonlinear interactions within the radius of maximum wind (RMW). However, the nonlinearity of these complex interactions may lower the predictability of TC intensity. In particular, predicting rapid intensification (RI) is much more difficult using numerical models implanted with parameterizations of these processes. In previous studies, RI is generally defined as when the minimum sea level pressure decreases by $42 \mathrm{hPa}$ or the maximum surface wind increases by $30 \mathrm{kt}\left(1 \mathrm{kt} \approx 0.51 \mathrm{~m} \mathrm{~s}^{-1}\right)$ within $24 \mathrm{~h}$ (Holliday and Thompson 1979; Kaplan and DeMaria 2003).

According to Kaplan and DeMaria (2003) and Lee et al. (2016), RI frequently occurs when the cyclone is at tropical storm intensity $\left(18 \leq V_{\max } \leq 32 \mathrm{~m} \mathrm{~s}^{-1}\right)$. The wind-induced surface heat exchange (WISHE) mechanism may explain TC intensification through a positive feedback between the wind and surface heat fluxes (Emanuel 1986). Many studies have assessed the values 
of surface exchange coefficients for enthalpy and drag based on either observations or numerical experiments and investigated their impact on TC intensity (Emanuel 1995; Powell et al. 2003; Donelan et al. 2004; Green and Zhang 2013). According to Emanuel (1995), this relation can be simply explained as follows. Based on the relationship between enthalpy $\left(C_{k}\right)$ and drag $\left(C_{d}\right)$ coefficients, when the Ekman inflow is large, the small value of $C_{k} / C_{d}$ indicates that the inflow air has low enthalpy (low equivalent potential temperature $\theta_{e}$ ). On the other hand, if the value of $C_{k} / C_{d}$ is large, this indicates that the inflow has high enthalpy (high $\theta_{e}$ ). As a result, transport of high enthalpy air into the eyewall is favorable for TC intensification. Observational and laboratory studies show that the drag coefficient tends to remain constant or slightly decrease above $33 \mathrm{~m} \mathrm{~s}^{-1}$ wind speed, because of the limited aerodynamic roughness of surface waves (Powell et al. 2003; Donelan et al. 2004). However, many studies have reported that the enthalpy coefficient tends to have larger uncertainty in high-wind environments (Andreas 2011; Green and Zhang 2013; Richter et al. 2016). In spite of this uncertainty, it is clear that strong winds can affect the surface heat fluxes and inertial stability near the RMW. In particular, for a closed polygonal eyewall within the RMW, varying magnitudes of surface heat fluxes and inertial stability are observed at each vertex region because of the locally enhanced tangential winds. Polygonal eyewall structures are believed to develop because of barotropic or baroclinic instabilities (Schubert et al. 1999; Rozoff et al. 2009; Menelaou et al. 2013; Hendricks et al. 2014), the inclusion of clouds that can slow the growth of phase-locked counterpropagating vortex Rossby waves (Schecter and Montgomery 2007), and the Rossby inertia buoyancy through couplings between vortex Rossby waves and the inertia buoyancy (Hodyss and Nolan 2007). Since polygonal eyewalls in the lower troposphere are rarely seen because of deep convective clouds and spatial resolution through the satellite imagery, observational studies primarily depend on aircraft data obtained by airborne radar. According to Lewis and Hawkins (1982), Hurricane Anita (1977)-enhanced radar reflectivity was evident at each vertex of a polygonal eyewall at about 3-km height during the RI period, with similar features observed in Hurricane Dolly (2008; Hendricks et al. 2012). Such polygonal eyewall structures tend to be less pronounced in the mid- and upper troposphere (Hendricks et al. 2012, see their Fig. 6). Similar characteristics are also found in numerical studies of RI. In numerical simulations of RI in Hurricane Wilma (2005), enhanced radar reflectivity and potential vorticity (PV) were observed at each vertex of the polygonal eyewall near the RMW (Menelaou et al. 2013). These polygonal eyewall structures may be sensitive to diabatic heating within the RMW (Hendricks et al. 2014; Wu et al. 2016a). In particular, if there is persistent net heating within the RMW where the inertial stability is large, it can contribute greatly to TC intensification, especially for RI (Hendricks et al. 2014).

In addition to polygonal eyewall structures, convective bursts (CBs) inside the RMW may also be an important factor in RI (Kelley and Halverson 2011; McFarquhar et al. 2012; Rogers 2010; Rogers et al. 2013, 2015). As shown in Rogers et al. (2013), intensifying TCs (when $V_{\max }$ intensifies by at least $20 \mathrm{kt}$ within $24 \mathrm{~h}$ ) have a much greater number of CBs within the RMW than steady-state TCs (when the change of $V_{\max }$ is maintained between $\pm 10 \mathrm{kt}$ within 24h). In addition, Kelley and Halverson (2011) quantitatively analyzed the latent heat release of CBs located inside the RMW. They found that CBs within the RMW can release about $7 \times 10^{17} \mathrm{~J}$ of latent heat in $12 \mathrm{~h}$, which can increase the maximum surface wind speed by $9-16 \mathrm{~m} \mathrm{~s}^{-1}$. This increase in maximum surface wind speed is great enough to satisfy the RI definition proposed by Kaplan and DeMaria (2003). Based on previous studies, the favorable conditions or distinct characteristics associated with RI can be summarized as follows:

- The existence of a low-level convective ring and its contraction to the RMW (Willoughby et al. 1982; Nolan and Grasso 2003; Vigh and Schubert 2009; Kieper and Jiang 2012; Miyamoto and Takemi 2015)

- The existence of energetic CBs and the upward transport of hydrometeors within the RMW (Chen and Zhang 2013; Rogers 2010; Rogers et al. 2013, 2015; McFarquhar et al. 2012; Chang and Wu 2017)

- The existence of deep convective cells on the downshear side with moderate and persistent VWS (Reasor et al. 2009; Rogers et al. 2013; Wang and Wang 2014; Chen and Gopalakrishnan 2015)

- A significant drop in eye excess energy defined as the difference of equivalent potential temperature between the eye and eyewall (Barnes and Fuentes 2010)

This study investigates the relationship between the RI and polygonal eyewalls in Typhoon Megi (2010), a devastating typhoon in the western Pacific basin. This paper is organized as follows. Section 2 introduces the data and model configuration used in this study. Section 3 provides an overview of Megi. For high-quality numerical simulations, a dynamical initialization (DI) method is illustrated in section 4. Section 5 describes several results with comparison between two different microphysics schemes. In section 6, we discuss how deep convective cells can develop on the downshear side of Megi and how the vertical alignment of the eyewall structure can be achieved during the RI period. Finally, a summary and the conclusions will be given in section 7 . 


\section{Data and model configuration}

This study uses the Advanced Research version of WRF (WRF-ARW), version 3.6.1 (Skamarock et al. 2008), with full physics to conduct high-resolution simulations of Megi. For this work, the $0.25^{\circ}$ ERA-Interim data produced by the four-dimensional variational analysis (4D-VAR) method from the European Centre for Medium-Range Weather Forecasts is used for the initial and lateral boundary conditions in the WRF model. The domains are configured as vortex-following triple-nested domains with two-way interaction (only for the second and third domains) with $421 \times 301$ (first; $18 \mathrm{~km}$ ), $211 \times 211$ (second; $6 \mathrm{~km}$ ), and $361 \times 361$ (third; $2 \mathrm{~km}$ ) grid points. Each domain has 40 uneven $\eta$ vertical levels, and the model top is set as $50 \mathrm{hPa}$. For example, assuming that the criteria of the lower and midtroposphere are 800 and $300 \mathrm{hPa}$, the vertical levels are assigned with $11 \eta$ levels in the lower troposphere, $12 \eta$ levels in the midtroposphere, and $17 \eta$ levels in the upper troposphere. Therefore, there are more $\eta$ levels at the upper levels. This study employs the following physical parameterization options: WRF single-moment 6-class (WSM6) and WRF double-moment 6-class (WDM6) microphysics schemes (Hong and Lim 2006; Lim and Hong 2010), Yonsei University (YSU; Hong et al. 2006), Mellor-Yamada-Janjić (MYJ; Janjić 1994), MellorYamada-Nakanishi-Niino (MYNN; Nakanishi and Niino 2006) 2.5-level (MN2.5) and 3.0-level (MN3) PBL schemes, the revised Fifth-generation Pennsylvania State UniversityNational Center for Atmospheric Research Mesoscale Model (MM5) surface-layer scheme (Jiménez et al. 2012), the five-layer thermal diffusion scheme for land surface processes, Rapid Radiative Transfer Model for an application to general circulation models as relative to the longwave and shortwave radiation effects (Iacono et al. 2008), and the Kain-Fritsch scheme for the subgrid deep and shallow convection only activated in the outmost domain (Kain 2004). To address the issue of numerical instability in the initial data, digital filter initialization (DFI) with a Dolph filter is applied twice, which is a recommended DFI option (Lynch and Huang 1994; Lynch 1997). For example, before the main numerical model integration, the model is integrated backward in time for an hour and then forward in time for half an hour.

\section{Overview of Typhoon Megi (2010)}

According to the Japan Meteorological Agency (JMA) best track data, Megi was named as a tropical storm at 1200 UTC 13 October over the western North Pacific. Prior to its RI event, Megi intensified to typhoon intensity while moving northwestward, with a minimum sea level pressure of $960 \mathrm{hPa}$ and a maximum surface wind speed of $75 \mathrm{kt}$. At 0000 UTC 16 October, Megi began to undergo RI. From 0000 UTC 16 October to 17 October, the JMA best track shows an abrupt intensification in its minimum sea level pressure and maximum surface wind, with the former decreasing by $45 \mathrm{hPa}$ and the latter increasing by $30 \mathrm{kt}$. Although the 10 -min-averaged maximum surface wind of the JMA looks weak, its 1-min-averaged maximum surface wind converted by using the equation $V_{1}=\left(V_{10}-10\right) / 0.64$, proposed by Knapp and Kruk (2010), is considerably strong, for example, increasing by $46.8 \mathrm{kt}$ in $24 \mathrm{~h}$. As a result, this period is designated as the RI period of Megi in this study. According to both observational and numerical studies, Megi was affected by high SST and OHC regions (D'Asaro et al. 2014; Wu et al. 2016b). This implies that Megi was in favorable environmental conditions for RI due to offsetting of cold wakes induced by the TC itself. Megi also entered an environment with weak VWS during the RI period (Wang and Wang 2014). During this abrupt intensification period, a distinct eye and solid eyewall structures are identified through Multifunctional Transport Satellite-1R (MTSAT-1R) imagery with 4-km spatial resolution (Fig. 1). Although there are considerable limitations in using these satellite images for identifying polygonal eyewalls in the mid- or lower troposphere, the colder brightness temperature indicating $193 \mathrm{~K}$ hint that the deep convective cells have an asymmetric structure, indicating the existence of real polygonal structures in the lower troposphere (Fig. 1). In particular, a distinct triangular eye and eyewall is identified (Figs. 1d,i). After the end of the RI event, Megi slowly further intensified and made landfall in the Philippines within $24 \mathrm{~h}$. At this time, Megi recorded a minimum sea level pressure of $885 \mathrm{hPa}$ and a maximum surface wind of $125 \mathrm{kt}$. Such an unexpected intensification event can cause significant socioeconomic damage due to insufficient evacuation time.

\section{DI method}

Simulated TC vortices that are too weak compared to best track observations frequently fail to spinup during model integration (Kurihara et al. 1993). In general, the initial conditions given by global models tend to describe the coarse TC structure and have comparatively weak intensity due to insufficient horizontal and vertical resolution. This leads to poor performance in track and intensity forecasts. To date, many studies have tackled this problem using a variety of TC-initialization methods, such as a bogus vortex, 3D- or 4D-variational assimilation, ensemble Kalman Filter, and DI (Kurihara et al. 1993; Zou and Xiao 2000; Kwon and Cheong 2010; Wu et al. 2010; 

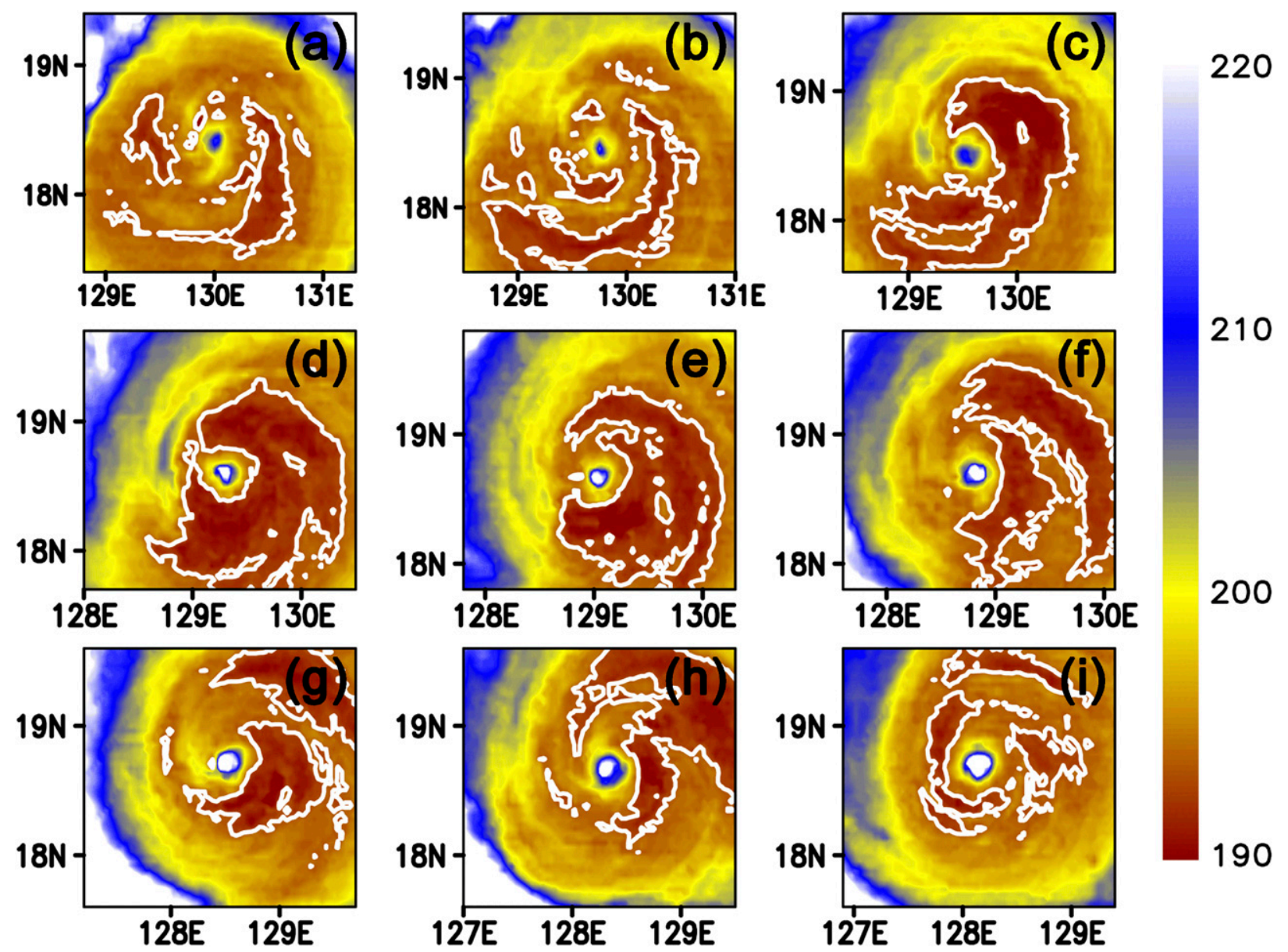

FIG. 1. The brightness temperature (MTSAT-1R IR2 channel between 11.5 and $12.5 \mu \mathrm{m}$ with 4-km resolution) during the RI period of Megi from (a) 1230 to (i) 2030 UTC 16 October 2010 with a 1-h interval. The white contour indicates 193-K brightness temperature.

Zhang et al. 2012; Cha and Wang 2013). These initialization methods have significantly reduced the spinup problem in numerical model simulations, though some still have weaknesses, such as the TC vortex's imbalance with its environment.

The DI procedure used in this study is from the bogus vortex initialization of Kurihara et al. (1993) and Kwon and Cheong (2010), while the vortex generation follows the DI methodology. Figure 2 shows the DI method developed for this study, consisting of the following four steps: 1) determination of the TC area, 2) application of the global/regional version of the high-order filter equation proposed by Cheong et al. $(2004,2015)$ and Park et al. (2011), 3) vortex-scale relocation, and 4) 6-h WRF Model integration with the activated DFI. The high-order filter equation decomposes a field into environment (large scale) and disturbance (vortex scale) fields according to the wavelength. In the first step of the DI process, a global version of the high-order filter equation is used to determine the TC area in the global domain by using the relationship between the vorticity and streamfunction, that is, $\psi=\nabla^{-2} \zeta$. For instance, because a negative normalized streamfunction represents cyclonic flow in the Northern Hemisphere, the extent of the TC can be determined based on the -0.1 streamfunction contour from the TC center. Next, the distance between -0.1 and 0 is exponentially connected with the environment. As seen in Fig. 2, during the DI process, the decomposed environmental scale is preserved in the same way as the global data (Fig. 2b), while the decomposed vortex scale is relocated to the best track position and is updated at every cycle run (Fig. 2c). In this DI process, the 12 variables describing the vortex are continually updated until the vortex reaches the best track intensity. The two-dimensional variables include 10-m horizontal winds, mean sea level pressure, 2-m temperature, 2-m relative humidity, surface temperature, and surface pressure, while the three-dimensional variables include horizontal winds, relative humidity, temperature, and geopotential. Figure 3 shows the evolution of 


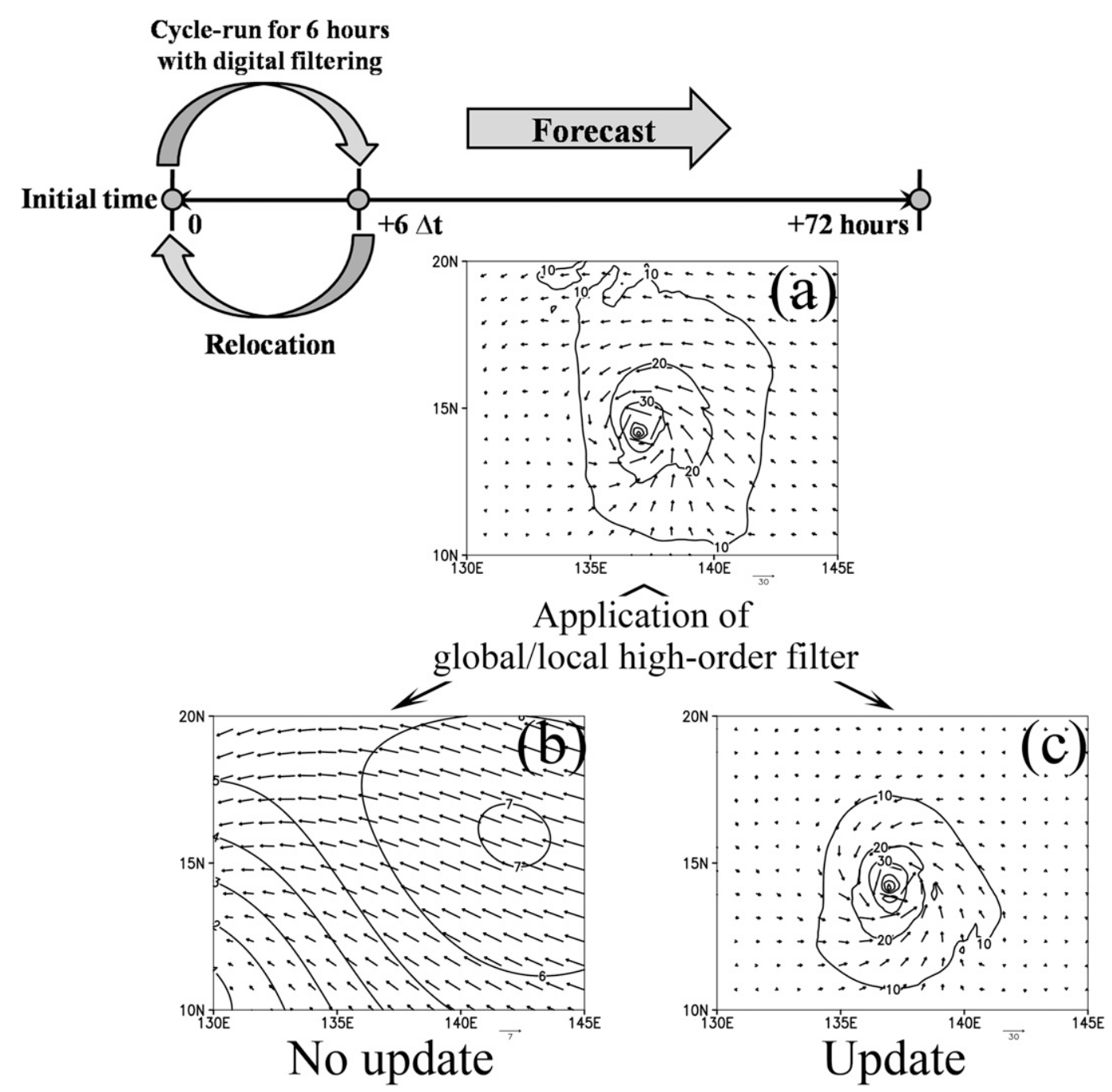

FIG. 2. A simple schematic illustration of the current DI method. The contours and vectors indicate the magnitude and direction of the horizontal wind at $1000 \mathrm{hPa}$. The horizontal wind field can be decomposed into the environment field (large scale) and disturbance field (vortex scale) using high-order filter equations according to wavenumbers, for example, (a) the horizontal wind field $\left(\mathbf{v}_{\max }=30 \mathrm{~m} \mathrm{~s}^{-1}\right)$ including all wavenumbers, (b) the environment field $\left(\mathbf{v}_{\max }=7 \mathrm{~m} \mathrm{~s}^{-1}\right)$ including wavenumbers $<14$, and (c) the disturbance field $\left(\mathbf{v}_{\max }=30 \mathrm{~m} \mathrm{~s}^{-1}\right)$ including wavenumbers $\geq 14$, respectively. During every cycle run, the vortex scale is only selectively updated.

the TC intensity and structure by applying this DI method. After the twelfth cycle run, the initialized vortex reaches 975-hPa minimum sea level pressure and $30.6 \mathrm{~m} \mathrm{~s}^{-1}$ maximum surface wind, which are comparable to the JMA best track intensity.

\section{Results}

\section{a. Sensitivity experiments with PBL and microphysics schemes}

According to Zhu et al. (2014), the choice of PBL scheme can significantly influence TC intensification. In addition, microphysics schemes may affect TC size through the interaction of hydrometeors with the radiative processes and thereby have the impact on TC track and intensity (Fovell et al. 2009, 2016). For these reasons, sensitivity experiments are conducted with various PBL schemes (YSU, MYJ, and MYNN2.5- and MYNN3.0-level) and microphysics schemes (WSM6 and WDM6), both to understand the impact of these parameterizations and to identify suitable parameterization options to simulate the RI processes in Megi. The microphysics and PBL schemes used in each experiment are outlined in Table 1.

The selected PBL and microphysics schemes are briefly introduced as follows. Prognostic number concentrations 

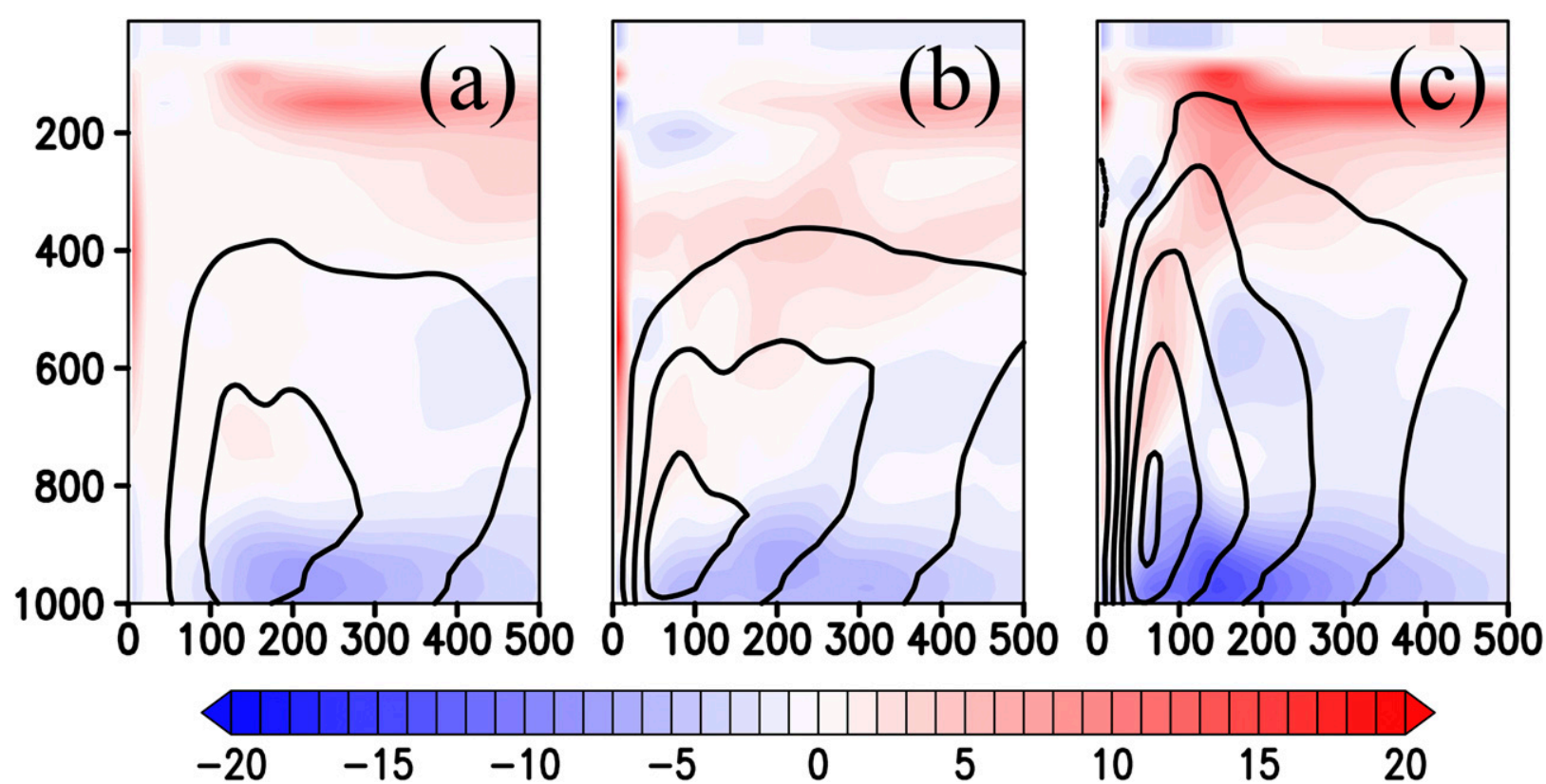

FIG. 3. The cross sections of tangential (contour; $\mathrm{m} \mathrm{s}^{-1}$ ) and radial wind structures ( $\mathrm{shaded} ; \mathrm{m} \mathrm{s}^{-1}$ ) of different cycle runs for (a) first run, (b) sixth run, and (c) twelfth run. The abscissa and ordinate indicate the radial distance $(\mathrm{km})$ and pressure level (hPa), respectively. The tangential wind is illustrated with a $8 \mathrm{~m} \mathrm{~s}^{-1}$ interval from the outmost contour. The tangential wind in the final cycle run reaches approximately $40 \mathrm{~m} \mathrm{~s}^{-1}$ at around $850 \mathrm{hPa}$.

of cloud and rainwater, which can indirectly influence ice processes, have been added to WDM6 together with cloud condensation nuclei (Lim and Hong 2010). These changes are not made in WSM6. The double-moment microphysical process for warm rain tends to better simulate heavy rainfall events associated with convection and also gives improved results for monsoonal summer precipitation in East Asia (Hong et al. 2010; Lim and Hong 2010). With regard to PBL schemes, the YSU scheme is formulated based on a nonlocal $K$ turbulent mixing with explicit entrainment. As a local vertical mixing scheme, the MYJ scheme includes the one-dimensional prognostic turbulent kinetic energy (TKE) terms, while the MYNN 2.5-level and 3.0-level schemes include the predicted three-dimensional subgrid TKE terms. Figure 4 presents the track, intensity, and
VWS results of the sensitivity experiments. Figure 4a shows considerable similarity to the simulated track of all the experiments. This may be as a result of the compact TC size, strong initial intensity, and dominant steering flow. After the onset of RI, differences in the intensity of the simulated TC begin to emerge between the experiments, even though they are in similar VWS environments (Figs. 4b-d). In particular, the double-moment microphysical process leads to weaker TCs. Based on the current RI definition, all WSM6 experiments meet the RI threshold, while all WDM6 experiments fail except for the case with the MYJ PBL scheme. After the onset of RI, the largest difference in the intensity of simulations between WSM6 and WDM6 experiments is observed with the MN3 PBL scheme. For example, during the RI period, WSM6-MN3 (WDM6-MN3) significantly

TABLE 1. The sensitivity experiments for PBL schemes and microphysics schemes in WRF, version 3.6.1.

\begin{tabular}{cccc}
\hline \hline Experimental cases & PBL parameterization & Microphysical parameterization & Surface-layer parameterization \\
\hline WSM6-YSU & YSU & WSM6 & Revised MM5 Monin-Obukhov \\
WSM6-MYJ & MYJ & WSM6 & Monin-Obukhov \\
WSM6-MN2 & MYNN2.5 & WSM6 & Revised MM5 Monin-Obukhov \\
WSM6-MN3 & MYNN3.0 & WSM6 & Revised MM5 Monin-Obukhov \\
WDM6-YSU & YSU & WDM6 & Revised MM5 Monin-Obukhov \\
WDM6-MYJ & MYJ & WDM6 & Monin-Obukhov \\
WDM6-MN2 & MYNN2.5 & WDM6 & Revised MM5 Monin-Obukhov \\
WDM6-MN3 & MYNN3.0 & WDM6 & Revised MM5 Monin-Obukhov \\
\hline
\end{tabular}



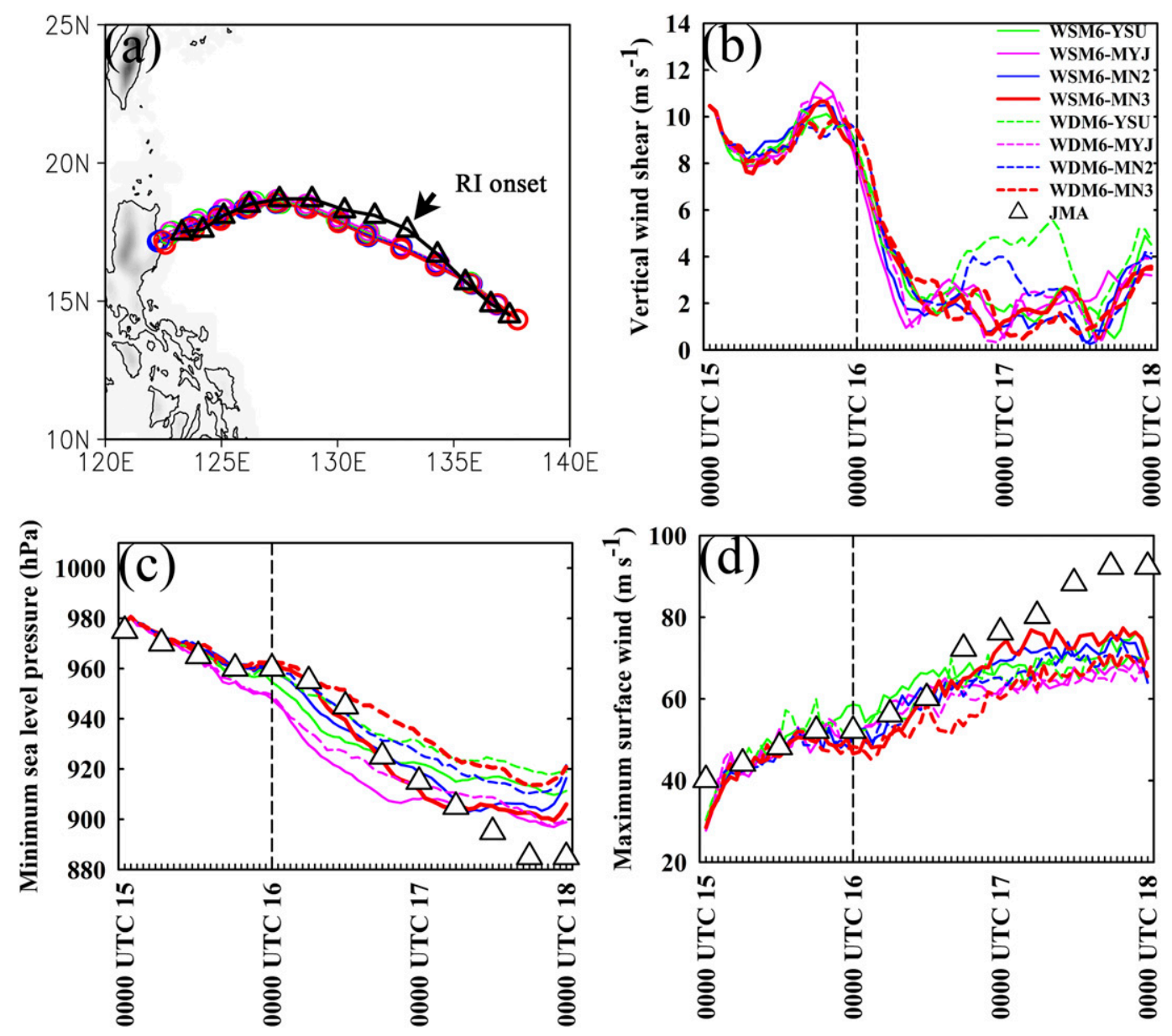

FIG. 4. Results of sensitivity experiments conducted with microphysics and PBL schemes for (a) track forecast, (b) VWS $\left(\mathrm{m} \mathrm{s}^{-1}\right)$, (c) minimum sea level pressure (hPa), and (d) maximum surface wind $\left(\mathrm{m} \mathrm{s}^{-1}\right)$. The solid (short dashed) lines indicate WSM6 (WDM6) microphysics experiments. The 10-min-averaged maximum surface wind speed is converted to the 1-min-averaged maximum surface wind speed by using the equation, that is, $V_{1}=\left(V_{10}-10\right) / 0.64$. The experiment cases shown in red line represent the largest differences in the minimum sea level pressure and maximum surface wind speed between WSM6 and WDM6. The VWS is computed by using the filtered large-scale winds as seen in Fig. $2 \mathrm{~b}$ between 1.8- and 12.1-km model heights.

intensifies with the minimum sea level pressure decreasing by $51(29) \mathrm{hPa}$ and the maximum surface wind increasing by $28(12) \mathrm{m} \mathrm{s}^{-1}$. In particular, WDM6-MN3 has the weakest intensity among all experiments, consistent with Zhu et al. (2014). Based on these results, this study investigates RI mechanisms by comparing the results of WSM6-MN3 (RI case) and WDM6-MN3 (non-RI case).

Figure 5 shows a time series of the hydrometeors $\left(q_{r}+\right.$ $\left.q_{c}+q_{s}+q_{g}+q_{i}\right)$ at 3-h intervals, defined as the sum of the mixing ratio of rainwater, cloud water, snow, graupel, and ice, respectively. Before the onset of RI, the distribution of hydrometeors is similar in WSM6-MN3 and WDM6-MN3. However, differences become apparent during the RI period. WSM6-MN3 has a narrow and upright vertical distribution of hydrometeors with the greatest vertical velocities concentrated in the midtroposphere and stronger inertial stability in the lower troposphere (Fig. 5a). On the other hand, WDM6-MN3 seems to have a slightly outward-tilted structure with weaker vertical velocities and inertial stabilities than that of WSM6-MN3 (Fig. 5b). In fact, as shown in Fig. 4 of Lim and Hong (2010), WDM6 microphysics tends to underestimate vertical velocities as compared to WSM6. The vertical profile of each hydrometeor is also consistent with the current study (not shown). As mentioned in Lim and Hong (2010), because the double-moment microphysical process tends to suppress light precipitation over the stratiform region, TCs with complex precipitation can be affected, especially below the melting level (see their Figs. $6 c$ and 6d). In other words, given that a humid environment in the lower troposphere 

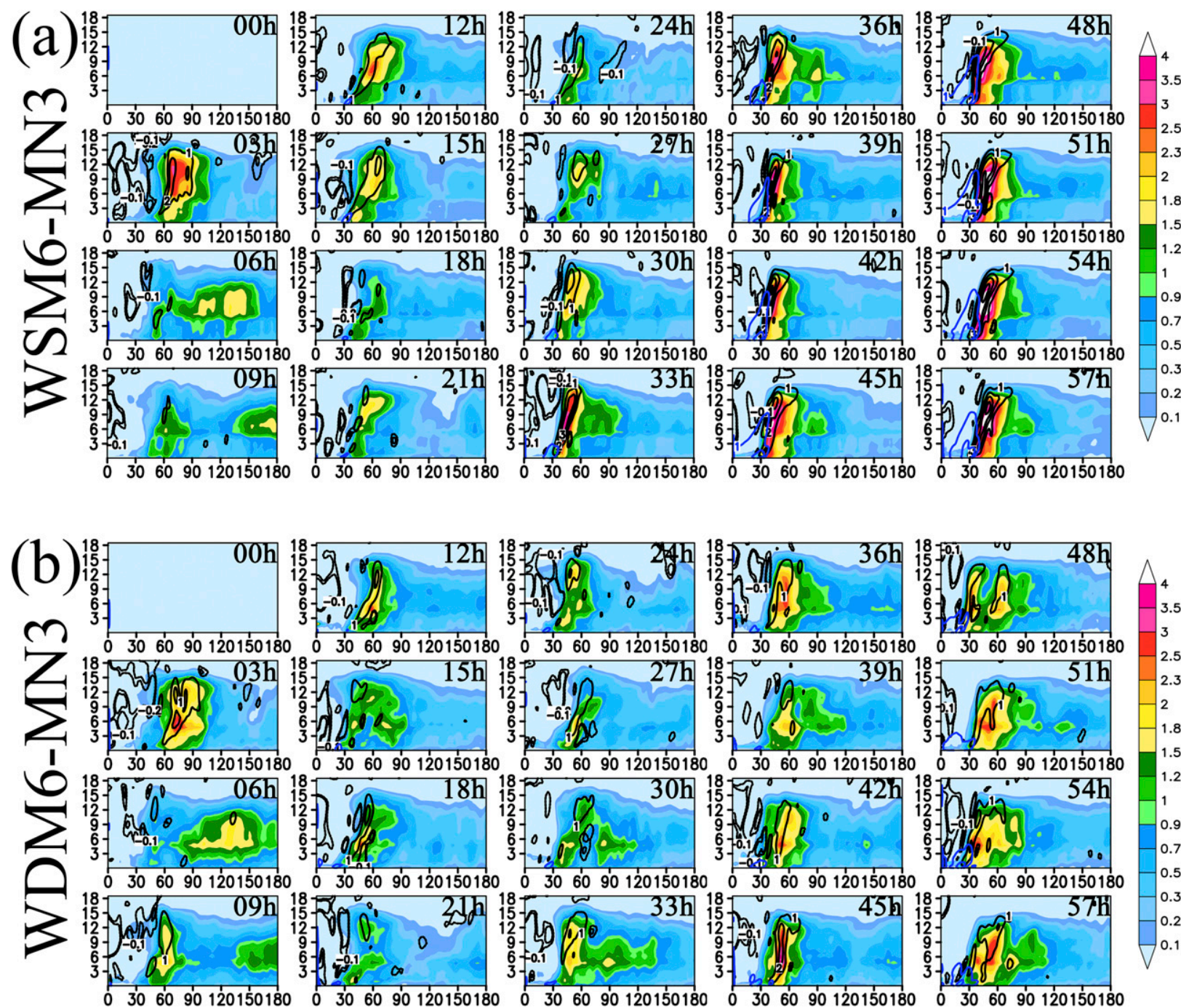

FIG. 5. Cross sections of azimuthally averaged hydrometeors $\left(10^{-3} \mathrm{~kg} \mathrm{~kg}^{-1} ; q_{r}+q_{c}+q_{s}+q_{g}+q_{i}\right.$; shaded area) superimposed with vertical velocities ( $\mathrm{m} \mathrm{s}^{-1}$; black contours) and inertial stabilities $\left(10^{-5} \mathrm{~s}^{-2}\right.$; blue contours) in the cases of (a) WSM6-MN3 and (b) WDM6-MN3 from 0000 UTC 15 October to 0900 UTC 17 October with a 3-h interval. Here, the RI period of the best track is from 24 to $48 \mathrm{~h}$.

creates favorable conditions for TC intensification, the relatively dry inner-core environment produced by WDM6 scheme could be unfavorable for intensification, especially RI. Figure 6 shows the difference between temperature and dewpoint temperature computed in cylindrical coordinates from 20 - to $100-\mathrm{km}$ radius and from near-surface to $1.5-\mathrm{km}$ altitude. Before the onset of $\mathrm{RI}$, the environment of WDM6-MN3 is drier in the lower troposphere than that of WSM6-MN3 (Fig. 6). Although this difference becomes small after the onset of RI, the local difference probably remains large. Contoured frequency by altitude diagrams (CFADs; Yuter and Houze 1995) is used to quantitatively analyze vertical velocities at different altitudes (Fig. 7). Before the onset of RI, strong updrafts are observed in the upper troposphere in both experiments (Figs. 7a,d). However, WDM6-MN3 also shows strong downdrafts around 4-km height (Fig. 7d), where the mixing ratio of the rainwater is large (not shown). In this environment, because the initial convective cell in the lower troposphere can collapse, the upward transport of the absolute vorticity, surface heat fluxes, absolute angular momentum (AAM), and hydrometeors from the lower troposphere is largely suppressed as compared to WSM6-MN3. Meanwhile, during the RI period, the region of maximum vertical velocity in WSM6-MN3 is displaced into the midtroposphere without significant weakening (Fig. 7b), while that in WDM6-MN3 is considerably weakened (Fig. 7e). In fact, these strong downdrafts are frequently observed in slowly intensifying or 


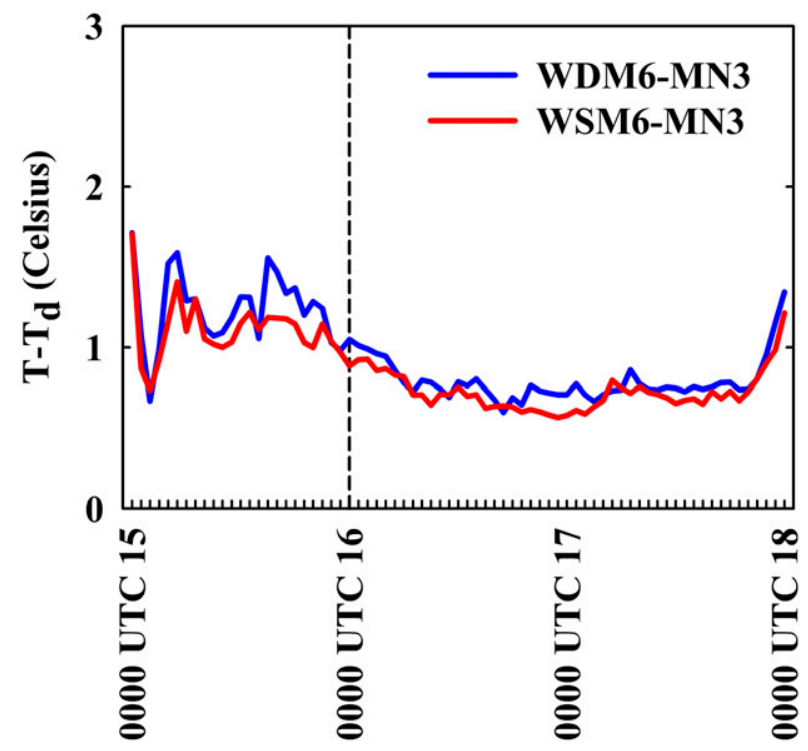

FIG. 6. The difference $\left({ }^{\circ} \mathrm{C}\right)$ between temperature and dewpoint temperature computed in cylindrical coordinates from 20- to $100-\mathrm{km}$ radius and from near-surface to about $1.5-\mathrm{km}$ altitude. The vertical dashed line indicates the onset of RI.

weakening TCs, which allow dry air to enter the eyewall from the outer environment.

\section{b. Characteristics of polygonal eyewalls in the lower troposphere}

Energetic convection tends to be observed at each major axis of a polygonal eyewall structure. Observational and numerical studies have shown that Hurricanes Anita (1977) and Wilma (2005) both displayed a clear polygonal eyewall during $\mathrm{RI}$, with radar reflectivity exceeding $45 \mathrm{dBZ}$ at 3-km altitude in the case of Anita and $50 \mathrm{dBZ}$ at $1.8-\mathrm{km}$ altitude in the case of Wilma (Lewis and Hawkins 1982; Menelaou et al. 2013). Previous studies have shown that these polygonal eyewalls can be attributed to barotropic instability or baroclinic instability (Schubert et al. 1999; Kossin and Schubert 2001; Rozoff et al. 2009; Menelaou et al. 2013) and the other mechanisms discussed in the introduction. Mesovortices are also frequently observed near the major axis of a polygonal eyewall (Kossin and Schubert 2001; Menelaou et al. 2013). As shown in Figs. 8 and 9, the simulated Megi also has a distinct polygonal eyewall structure with maxima of PV and horizontal wind located at each major axis at around 500-m model height. These results are quite consistent with Menelaou et al. (2013). In particular, the $20 \mathrm{PVU}\left(1 \mathrm{PVU}=10^{-6} \mathrm{~K} \mathrm{~kg}^{-1} \mathrm{~m}^{2} \mathrm{~s}^{-1}\right.$ ) line is thicker in WSM6-MN3 than in WDM6-MN3. Overall, the magnitude of the PV and horizontal wind is larger in WSM6-MN3 than in WDM6-MN3 at each vertex of polygonal eyewall. These local PV anomalies at each vertex of the polygonal eyewall can reinforce the ascending motion in front of the relatively high isentropic surface (Raymond and Jiang 1990, their Fig. 2). By Bernoulli's principle, when air parcels pass by the radially narrower and locally higher isentropic curved area, the vertical and horizontal velocities are enhanced around that locally higher isentropic area. If the area of supergradient wind is collocated with the higher isentropic area, this ascending motion may be further enhanced by overshooting flows (Gray and Shea 1973; Green and Zhang 2015).

The locally enhanced horizontal wind speed along a polygonal eyewall can greatly increase the surface heat fluxes and significantly contribute to TC intensification through the WISHE mechanism (Emanuel 1986). Consequently, the large PV and strong supergradient winds associated with polygonal eyewalls could be favorable for the formation of updrafts as well as the increase of horizontal winds in the lower troposphere. Rogers (2010) showed that the onset of RI could be associated with the increased vertical mass flux induced by convection in the lowest $1.5 \mathrm{~km}$ of altitude. A polygonal eyewall structure within the RMW may be a possible condition for increasing the vertical mass flux at each vertex region, eventually leading to RI.

Parseval's theorem is used to quantitatively estimate the shape of polygonal eyewalls as follows:

$$
\frac{1}{2 \pi} \int_{0}^{2 \pi} f(\theta)^{2} d \theta=\sum_{n=1}^{N}\left(a_{n}^{2}+b_{n}^{2}\right)
$$

where $N, a_{n}$, and $b_{n}$ indicate the total wavenumber and Fourier coefficients for the cosine and sine functions, and $f(\theta)$ indicates the azimuthal component of the PV in the cylindrical coordinate. In this calculation, the total wavenumber $N$ is taken to be 6 . The percentage of waves with different asymmetric wavenumbers can be computed based on a Fourier transform and Parseval's theorem. Figure 10 shows each asymmetric PV proportion calculated within $50-\mathrm{km}$ radius from the TC center. First, there is a clear change from a wavenumber-3 to wavenumber-4 structure in WSM6MN3 during the RI period, that is, from 0000 UTC 16 October to 0000 UTC 17 October. After the RI period, the wavenumber-4 PV structure reverts to a wavenumber-3 structure, with large PV and tangential wind (Figs. 8, 10a). Overall, the changes in PV wavenumber structure are more irregular in WDM6-MN3 than in WSM6-MN3, which maintains a wavenumber-3 and wavenumber-4 structure during the RI period. This result indicates that if certain polygonal eyewall structures are maintained with high inertial stability for an extended period of time, the eyewall structure may be 

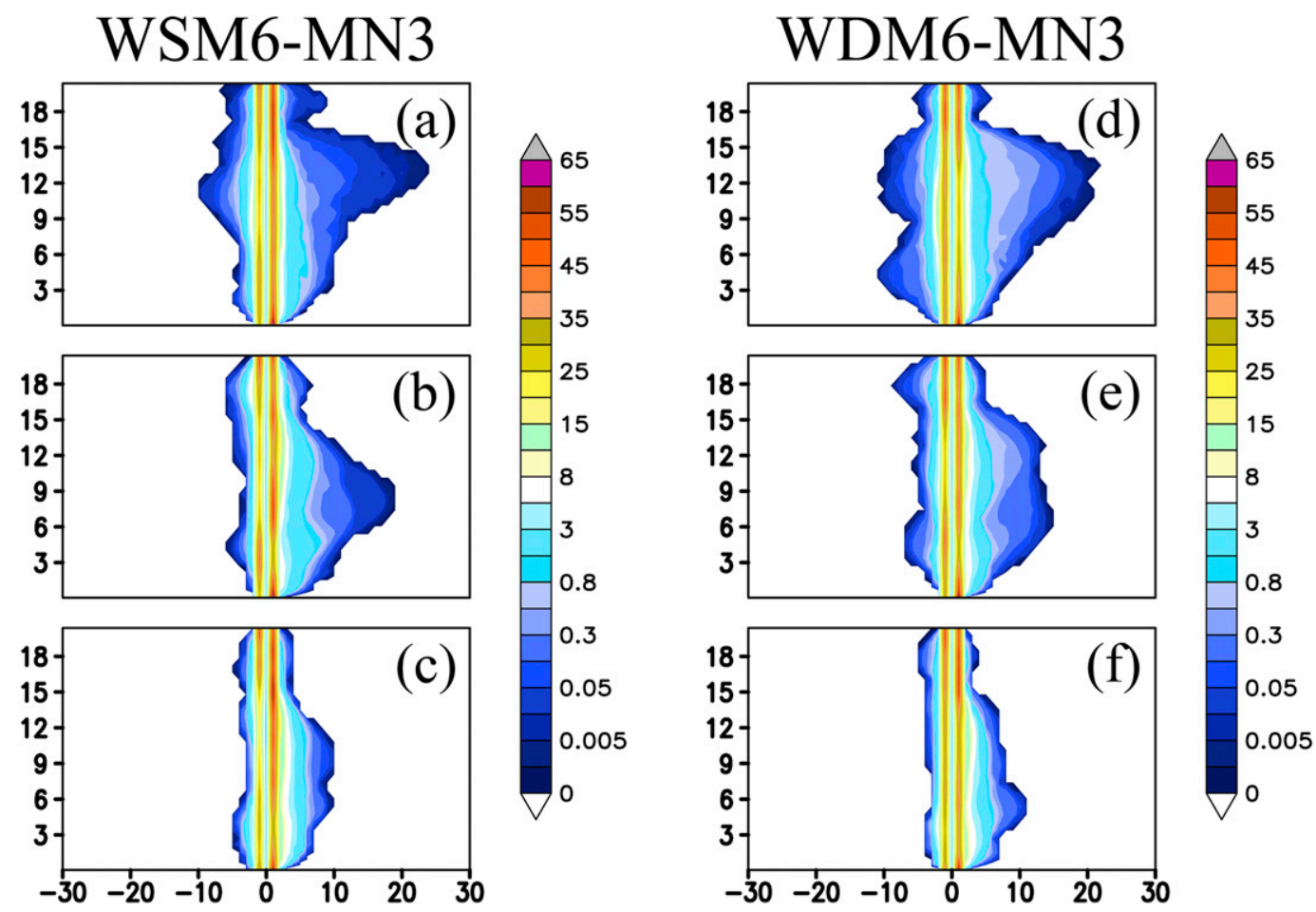

FIG. 7. The analyzed CFADs (\%) of vertical velocity $\left(\mathrm{m} \mathrm{s}^{-1}\right)$ from the center to $80-\mathrm{km}$ radius between WSM6MN3 and WDM6-MN3 (a),(d) before; (b),(c) during; and (c),(f) after the RI period. The shaded area indicates the percentages against the total vertical velocity, and the abscissa and ordinate represent the vertical velocity and altitude $(\mathrm{km})$, respectively.

more favorable for TC intensification. From this perspective, the eyewall structure in WSM6-MN3 may be more favorable for TC intensification in the lower troposphere during the RI period (Fig. 9). The more irregular PV structure observed in WDM6-MN3 means that it may be more difficult to maintain the kinetic energy than in the case of WSM6-MN3, especially during the axisymmetrization process (Wang 2002).

\section{c. The relationships between AAM and supergradient wind and between inertial stability and surface heat fluxes}

The persistent advection of large AAM into the eyewall may generate favorable conditions for the formation of supergradient wind in the boundary layer within the RMW (Kepert 2001; Kepert and Wang 2001). Once supergradient wind develops within the RMW, it can continually impact the tangential wind and radial inflow in the boundary layer. Consequently, the supergradient wind also has continual influence on the eyewall structure within the RMW. To understand the characteristics of the inner eyewall, the storm-relative absolute angular momentum $M$, net radial force $F$, and inertial stability $I^{2}$ are calculated based on (2)-(4), respectively, in a cylindrical coordinate system (Reasor et al. 2009; Li et al. 2012; Rozoff et al. 2012)

$$
\begin{aligned}
M & =\rho\left(r v_{\theta}+\frac{f r^{2}}{2}\right), \\
F & =-\frac{1}{\rho} \frac{\partial p}{\partial r}+\frac{v_{\theta}^{2}}{r}+f v_{\theta}, \text { and } \\
I^{2} & =(f+\zeta)\left(f+\frac{2 v_{\theta}}{r}\right),
\end{aligned}
$$

where $\rho, v_{\theta}, f, p, \zeta$, and $r$ are the air density, tangential wind, Coriolis force, pressure, relative vorticity, and radius, respectively. Figure 11 shows a comparison of the net radial force and radial advection of the AAM $\left(V_{r} \partial M / \partial r\right)$ at around 500-m model height in WSM6MN3 and WDM6-MN3 for prior to RI, during RI, and after RI, respectively. A common feature of both experiments is the distinct maxima where the radial AAM advection exceeds $-1.8 \times 10^{3} \mathrm{~kg} \mathrm{~m}^{2} \mathrm{~s}^{-2}$ at each vertex of polygonal eyewalls (Fig. 11). These maxima in the radial advection of the AAM tend to nearly coincide with the maximum in tangential wind, $\mathrm{PV}$, and area of supergradient wind at each vertex of the polygonal eyewall 


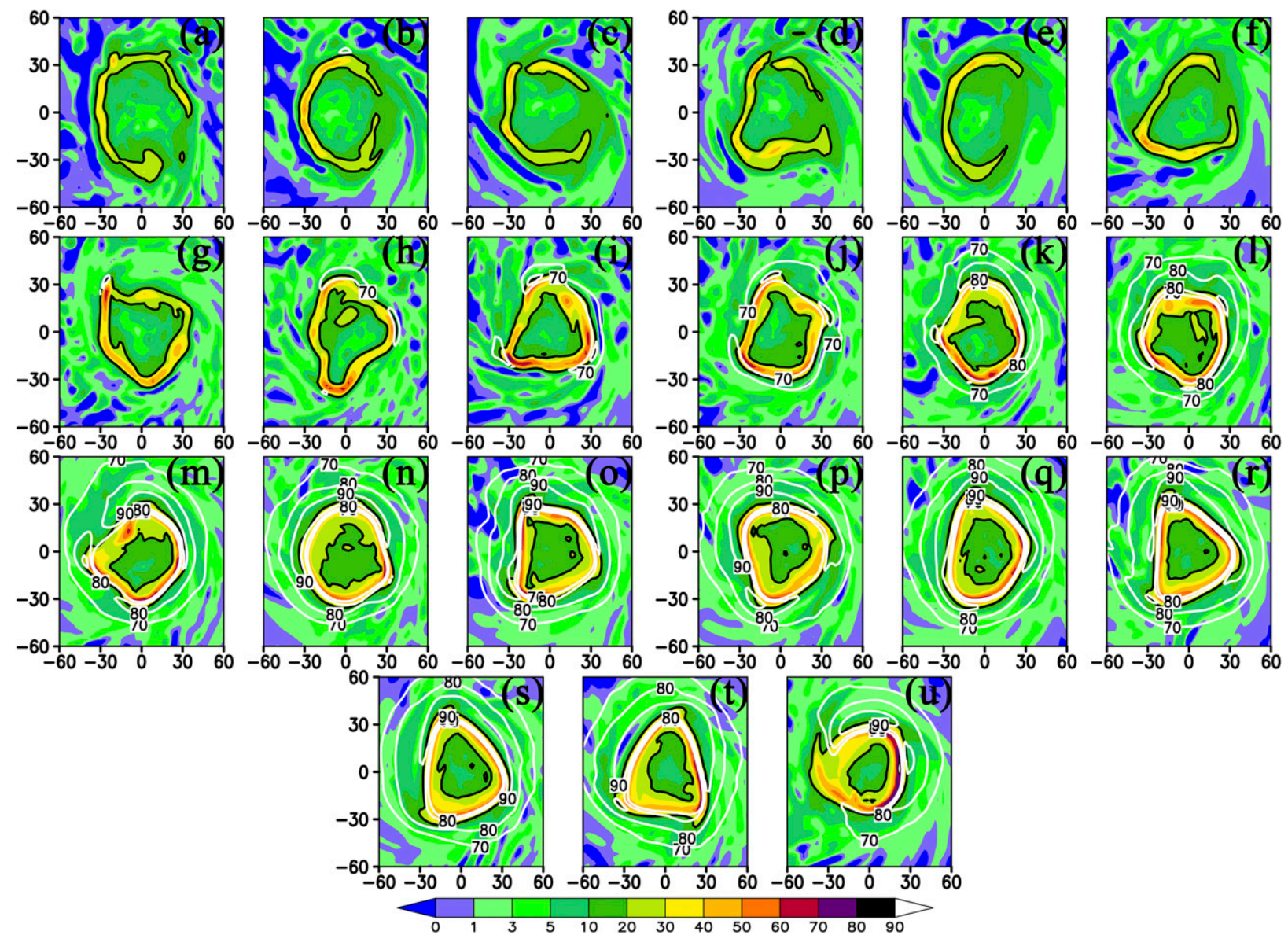

FIG. 8. The potential vorticity (PVU; shaded) of WSM6-MN3 superimposed with tangential wind ( $\mathrm{m} \mathrm{s}^{-1}$ ) at around 500-m model height. The PV field is displayed from (a) 1200 UTC 15 October to (u) 0000 UTC 18 October with a 3-h interval. The black contour indicates 20 PVU, and the white contours denote the tangential wind over $70 \mathrm{~m} \mathrm{~s}^{-1}$ with a $10 \mathrm{~m} \mathrm{~s}^{-1}$ interval. The RI period of the best track is from (e) to (m).

(Figs. 8, 9, 11). Although polygonal eyewalls exist in both cases during the RI period, WSM6-MN3 has a clearer and better-maintained polygonal eyewall in the lower troposphere especially during the RI period (Fig. 10).

Figure 12 shows the inertial stability and total surface heat fluxes. The total surface heat fluxes are computed directly from the WRF model by combining the latent and sensible heat fluxes. Interestingly, large total surface heat fluxes and inertial stability tend to develop at each vertex of the polygonal eyewall. This is due to the existence of stronger winds, leading to larger surface heat fluxes and larger inertial stability. During RI, the coincidence of higher surface heat fluxes exceeding $2200 \mathrm{~W} \mathrm{~m}^{-2}$ and regions of high inertial stability is greater in WSM6-MN3 than in WDM6-MN3. Although the total surface heat fluxes and inertial stability are smaller in WDM6-MN3 than WSM6-MN3, larger anomalies in these variables are observed at each vertex of the polygonal eyewall. This implies that inside the RMW, polygonal eyewalls favor TC intensification because of their generation of locally enhanced surface heat fluxes and inertial stabilities.

\section{d. The relationship between convective cells and warm-core development}

As discussed in previous papers, CBs within the RMW have been recognized as a key factor in RI (Chen and Zhang 2013; Rogers 2010; Rogers et al. 2013, 2015; Vigh and Schubert 2009; McFarquhar et al. 2012; Chang and $\mathrm{Wu}$ 2017). In some papers, CBs have been defined strictly by their vertical velocity (Montgomery et al. 2006; Rogers 2010). However, in this case, too many CBs are typically identified and estimates of the latent heat release from $\mathrm{CBs}$ could be inaccurate. To improve the identification of CBs, Reasor et al. (2009) defined CBs as regions where the vertical velocity and radar reflectivity at $2-\mathrm{km}$ height are over $5 \mathrm{~m} \mathrm{~s}^{-1}$ and $30 \mathrm{~dB} Z$, respectively. 

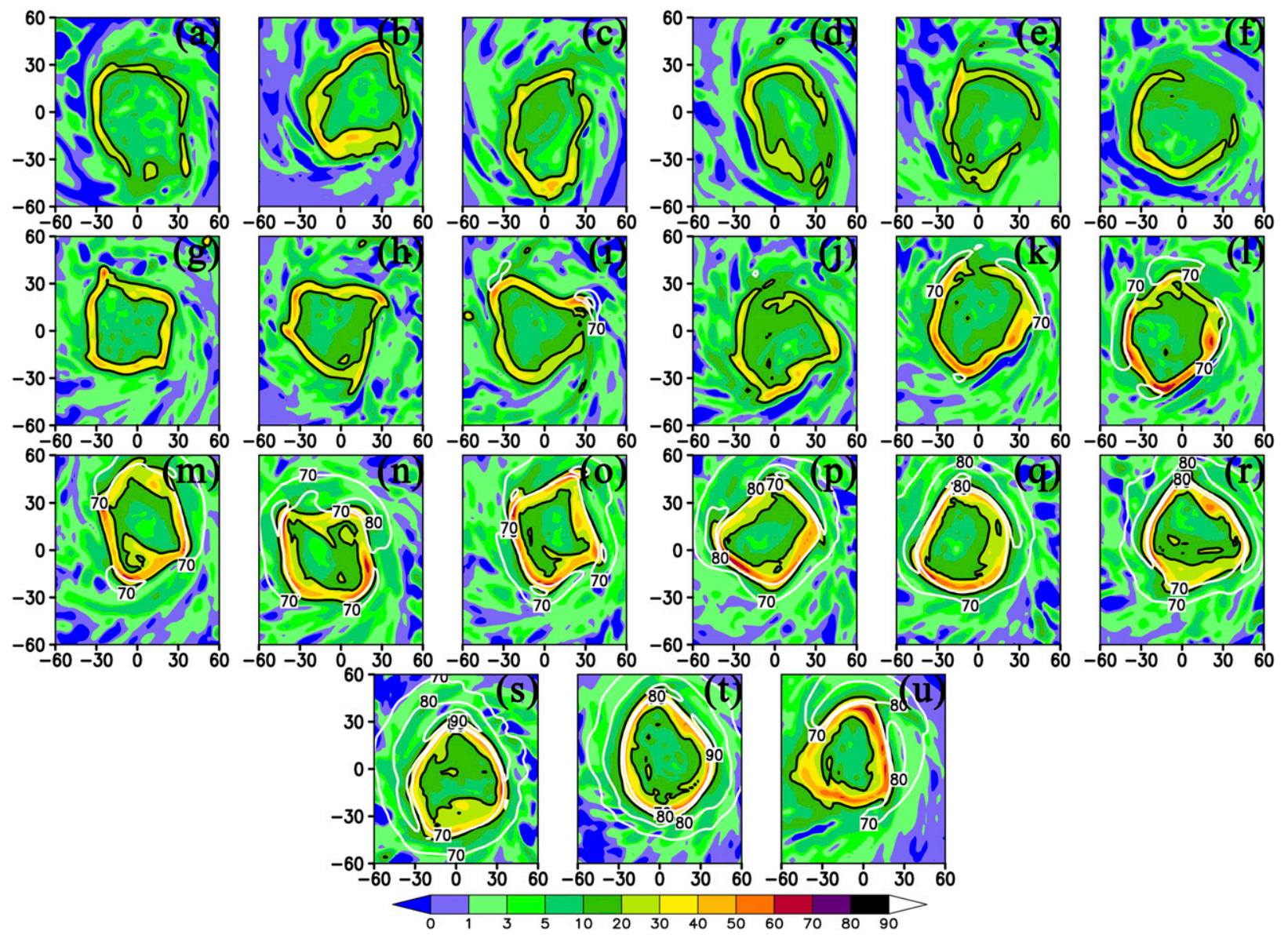

FIG. 9. As in Fig. 8, but for the WDM6-MN3 case.

As discussed in Kelley and Halverson (2011), the massive latent heat release produced by $\mathrm{CBs}$ within the eyewall can lead to abrupt intensification in the maximum surface wind from 9 to $16 \mathrm{~m} \mathrm{~s}^{-1}$ in $12 \mathrm{~h}$.
This intensification rate satisfies the RI definition proposed by Kaplan and DeMaria (2003). For further insight into CBs, convective updrafts are binned into the following vertical velocity levels: $1<w<3 \mathrm{~m} \mathrm{~s}^{-1}$ is classified as (a) WSM6-MN3

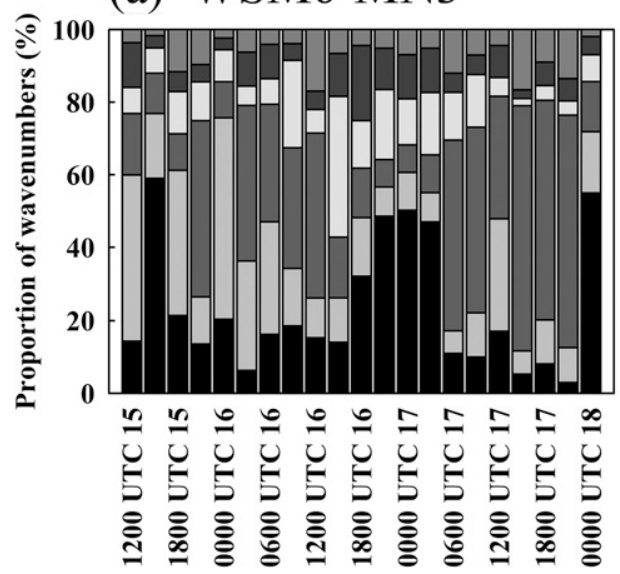

(b) WDM6-MN3

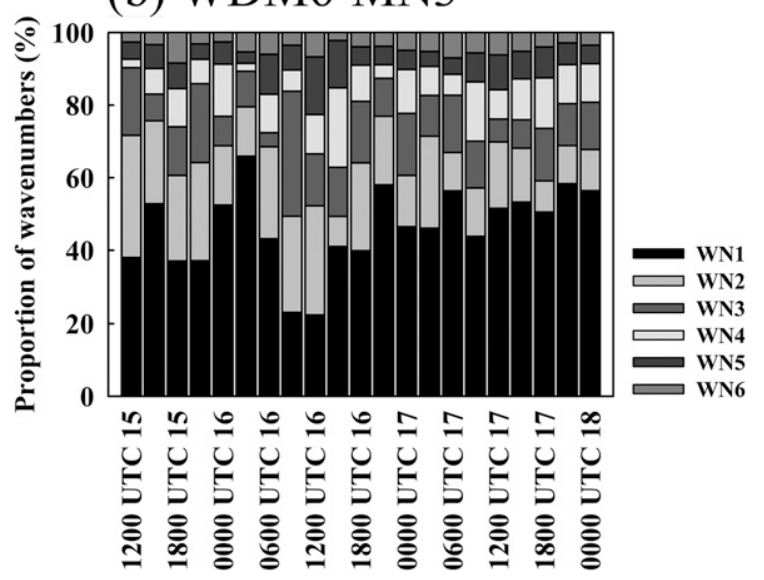

FIG. 10. The proportion of asymmetric waves computed from TC center to 50-km radius of (a) WSM6-MN3 and (b) WDM6-MN3 based on the PV field at around 500-m model height. The vertical bars are plotted with a 3-h interval. 

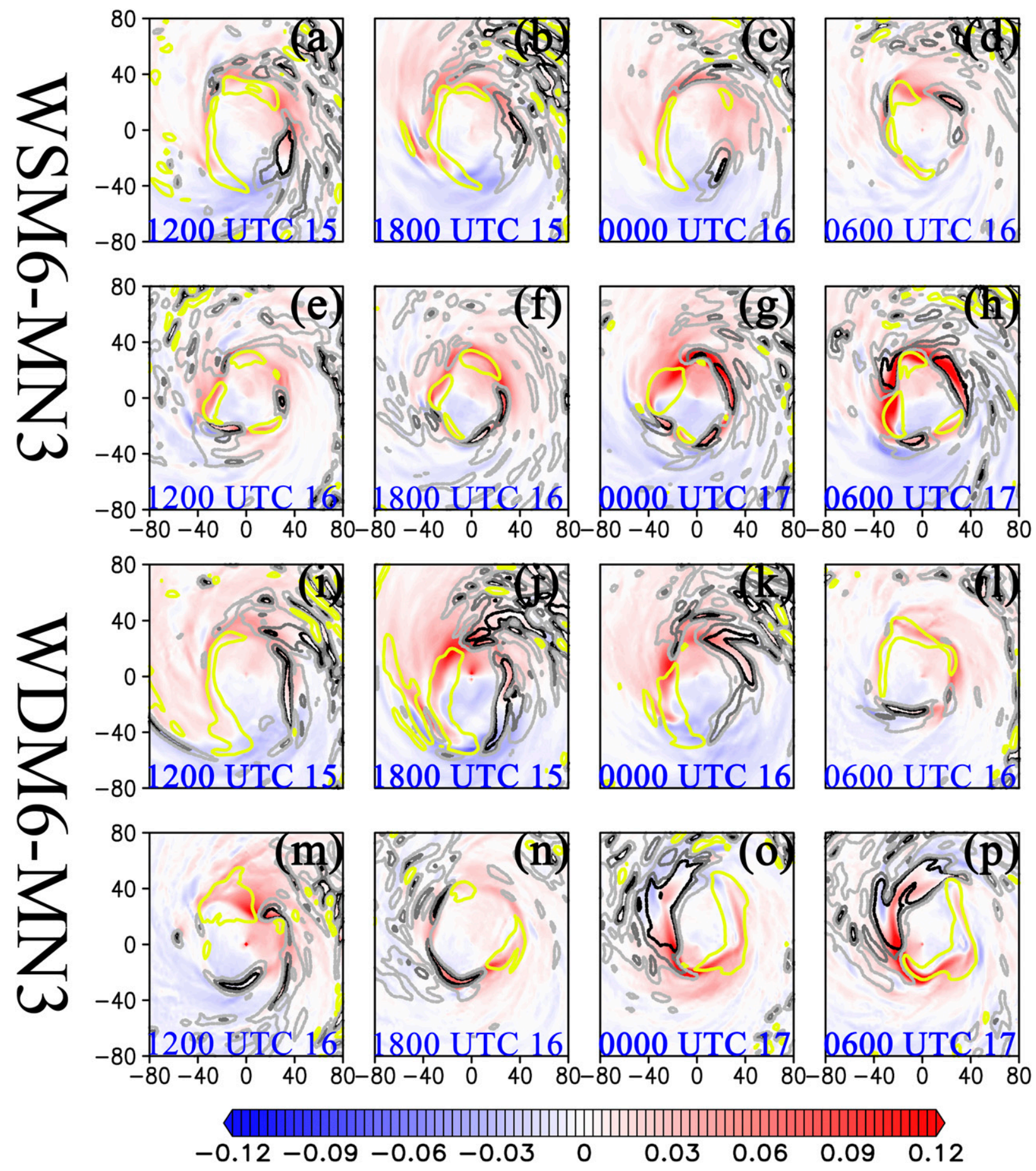

FIG. 11. The radial AAM advection $\left(v_{r} \partial M / \partial r ; 1.0 \times 10^{3} \mathrm{~kg} \mathrm{~m}^{2} \mathrm{~s}^{-2} ;\right.$ contour lines) superimposed with the net radial force ( $\mathrm{m} \mathrm{s}^{-2} ; \mathrm{shaded}^{2}$ area) between (a)-(h) WSM6-MN3 and (i)-(p) WDM6-MN3 at around 500-m model height. The panels show status prior to RI in (a),(b),(i), and (j); during RI in (c)-(g) and (k)-(o); and after RI in (h) and (p) with 6-h intervals. The positive (negative) shaded area indicates the supergradient wind (subgradient wind) area. The contours indicate the inward (outward) AAM advection, -1.8 in black, -1.2 in dark gray, -0.6 in light gray, and 0.6 in yellow. 

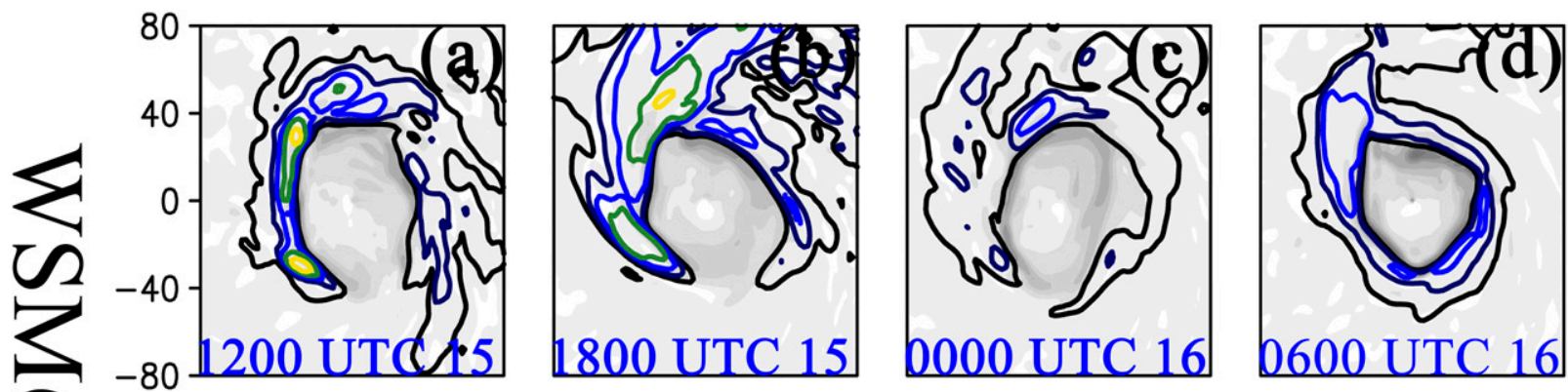

永
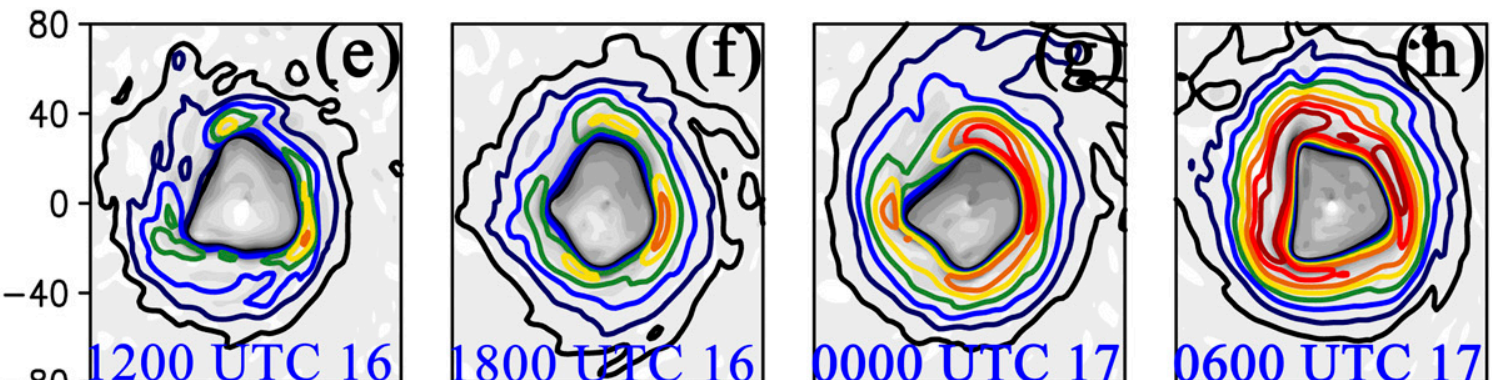

$-80+200$ UT, 16
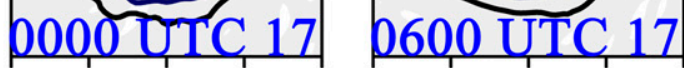

$-80-40 \quad 0 \quad 40 \quad 80-80-40 \quad 0 \quad 40 \quad 80-8$
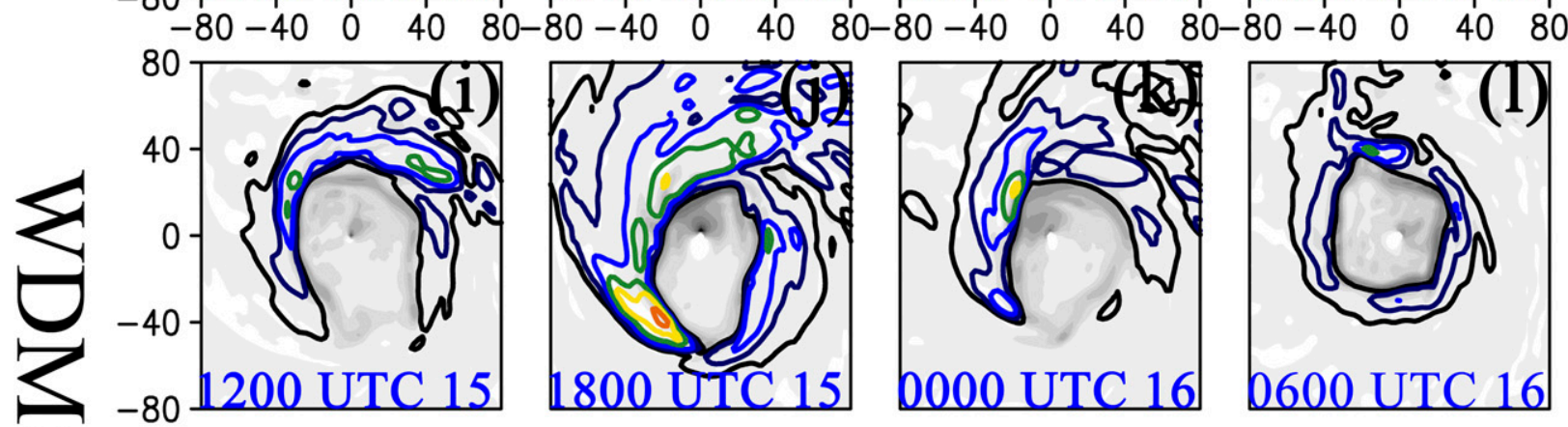

$\sum_{i}^{1}$

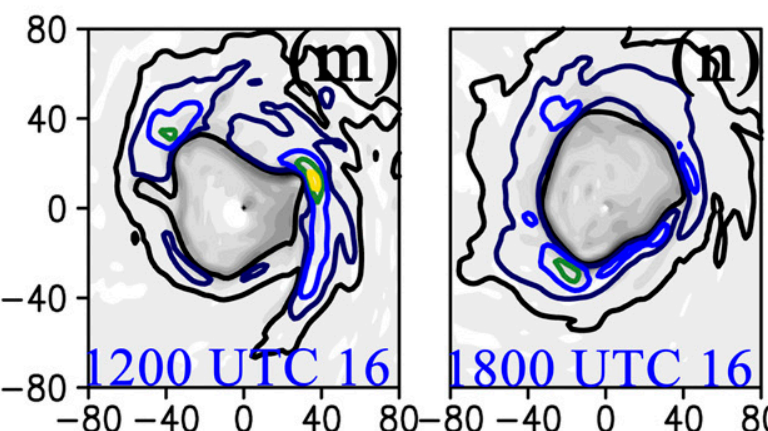

0000 UTC 16
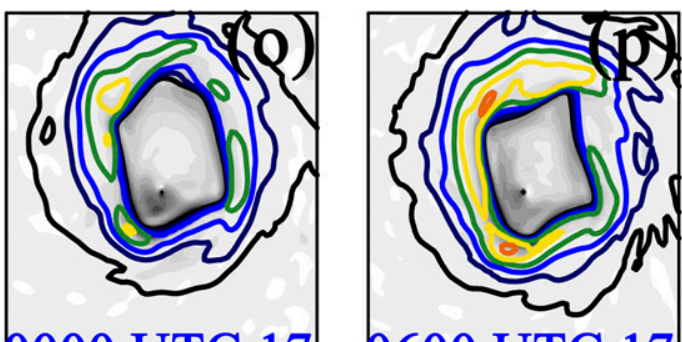

0000 UTC 17

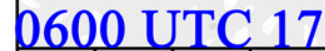

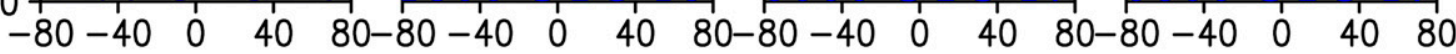

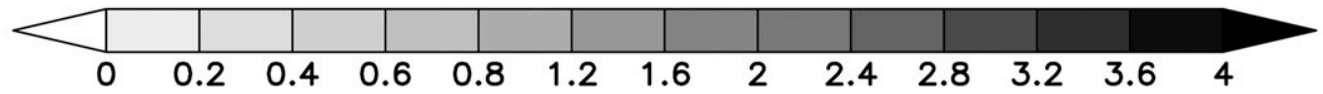

FIG. 12. As in Fig. 11, but for the inertial stability $\left(10^{-4} \mathrm{~s}^{-2}\right.$; shaded area) near surface (about $\left.50 \mathrm{~m}\right)$ superimposed with total surface heat fluxes ( $\mathrm{W} \mathrm{m}^{-2}$; contours). The color contours indicate the surface heat fluxes: $1400 \mathrm{~W} \mathrm{~m}^{-2}$ in black, $1600 \mathrm{~W} \mathrm{~m}^{-2}$ in dark blue, $1800 \mathrm{~W} \mathrm{~m} \mathrm{~m}^{-2}$ in blue, $2000 \mathrm{~W} \mathrm{~m}^{-2}$ in green, $2200 \mathrm{~W} \mathrm{~m}^{-2}$ in yellow, $2400 \mathrm{~W} \mathrm{~m}^{-2}$ in orange, $2600 \mathrm{~W} \mathrm{~m}^{-2}$ in red, and $2800 \mathrm{~W} \mathrm{~m}^{-2}$ in dark red.

weak convection, $3 \leq w<6 \mathrm{~m} \mathrm{~s}^{-1}$ is moderate convection, and $w \geq 6 \mathrm{~m} \mathrm{~s}^{-1}$ represents $\mathrm{CB}$. All convective updrafts have over $30-\mathrm{dB} Z$ radar reflectivity at 2-km model height.
Figure 13 shows the distribution of moderate convection superimposed with the radar reflectivity in WSM6-MN3 and WDM6-MN3 around 1.8-km model height during the RI period. Most moderate convection 

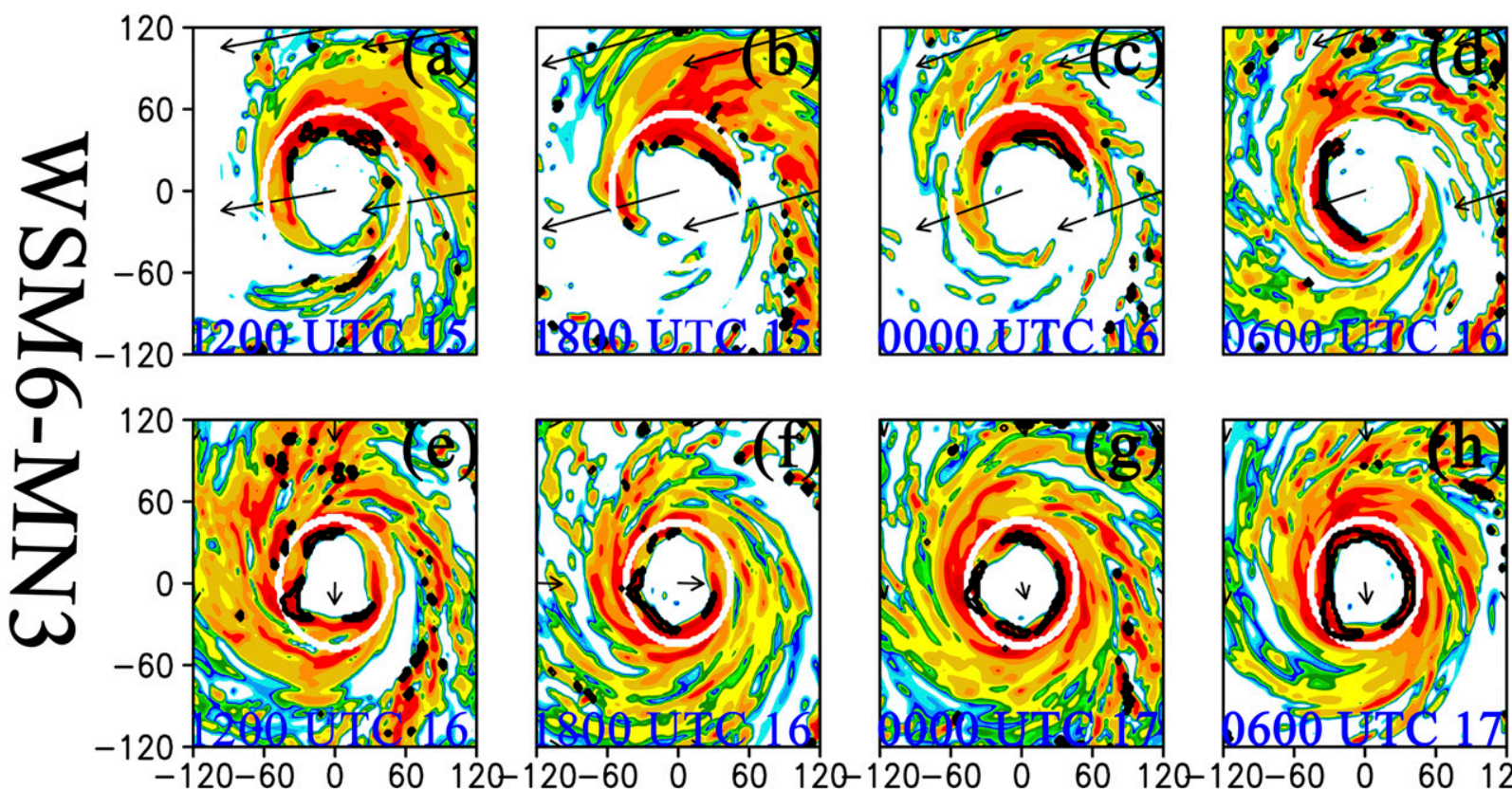

$-120-60 \quad 0 \quad 60 \quad 120$
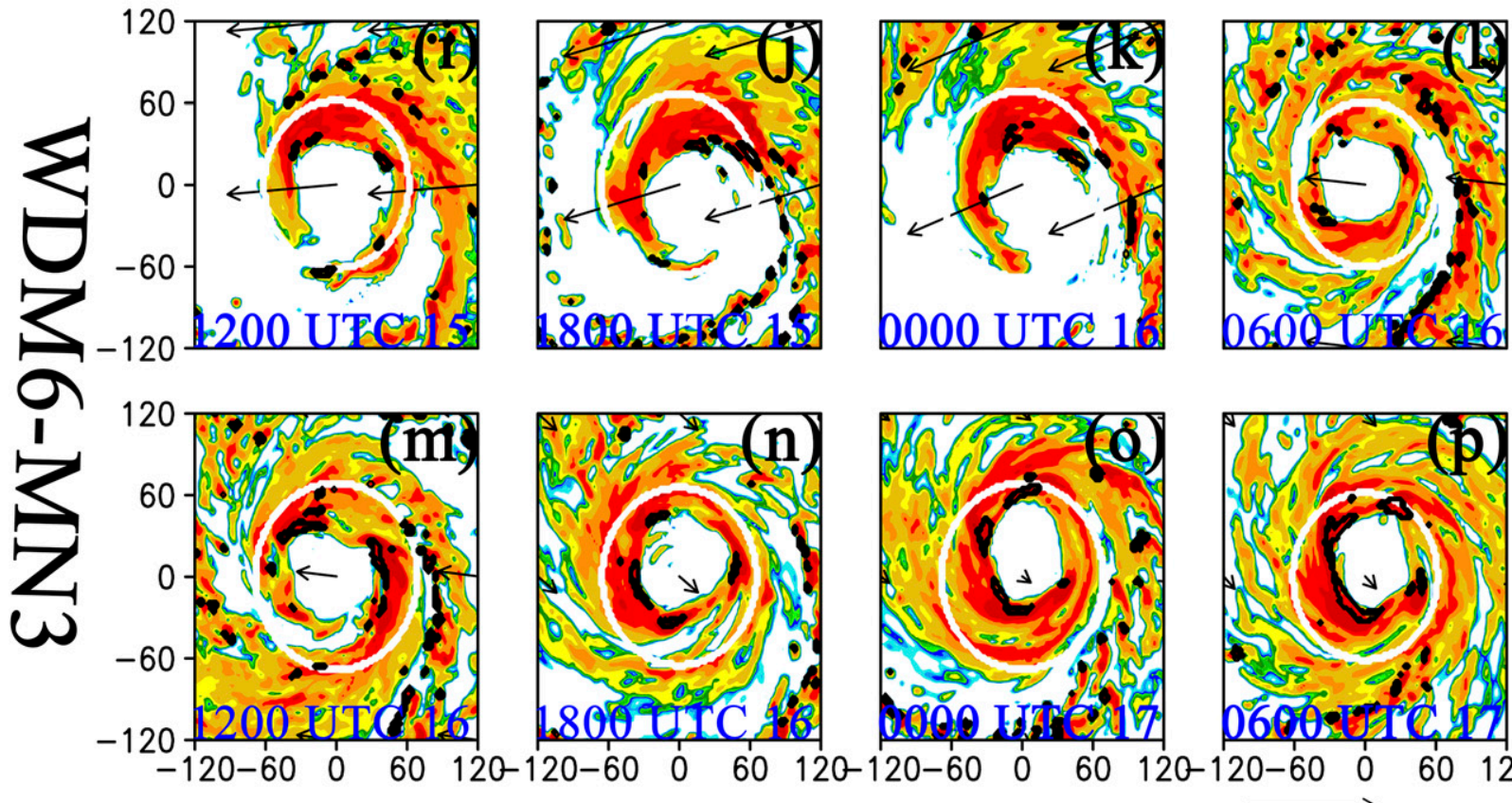

$60120-120-60$

$60120-120-60$

10

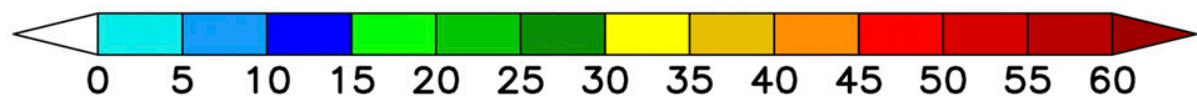

FIG. 13. As in Fig. 11, but for the radar reflectivity (dBZ; shaded area) superimposed with the moderate convection (black contour) around 1.8-km model height. The white circle indicates the RMW, and vectors denote the VWS calculated between 1.8- and 12.1-km model heights.

in both experiments seems to be collocated with the maximum values of radial AAM advection, inertial stability, PV, horizontal wind, and the surface heat fluxes at each vertex of polygonal eyewalls (Figs. 8, 9, 11, 12).
Although the moderate convection in WDM6-MN3 and WSM6-MN3 has a similar spatial distribution within the RMW, much more moderate convection is observed outside the RMW in WDM6-MN3 (Fig. 13). Because 
WSM6-MN3
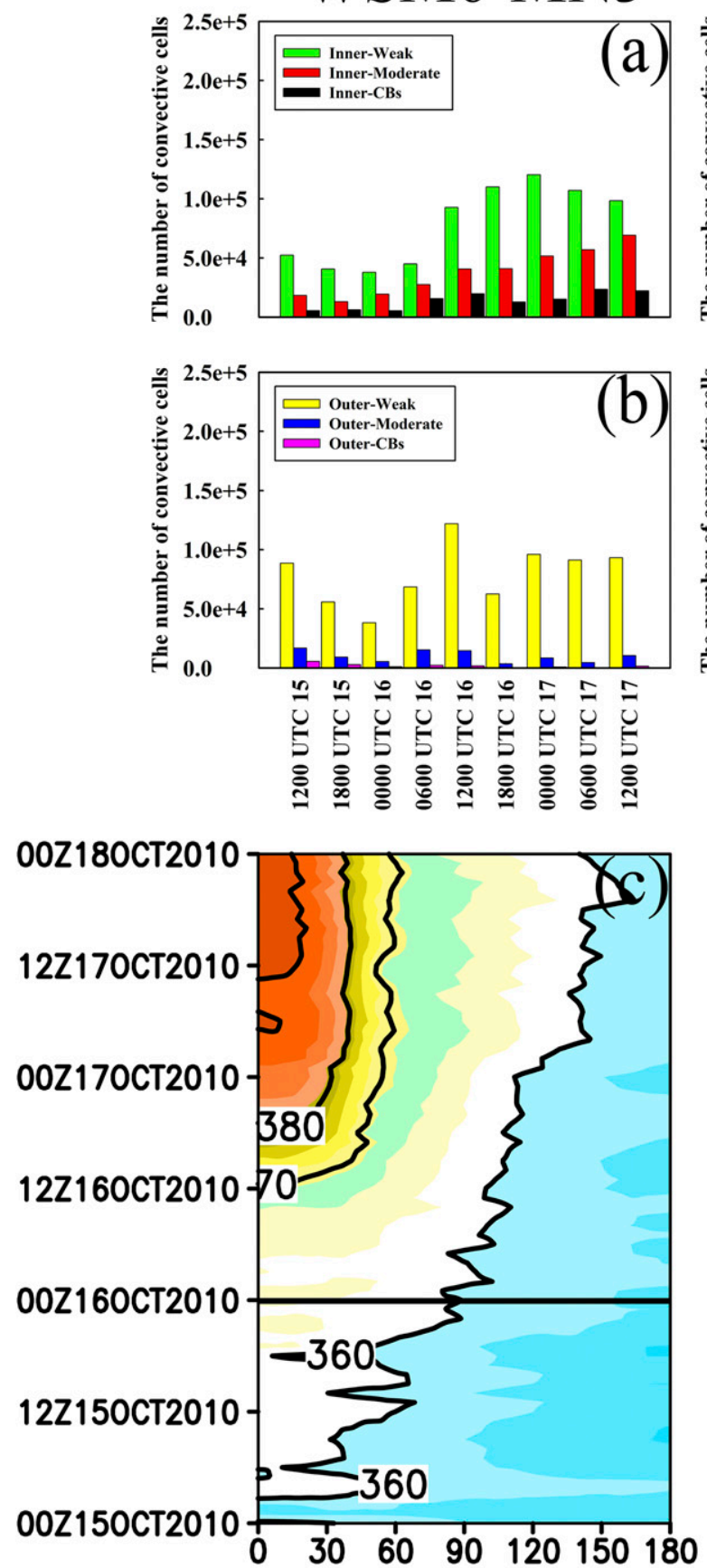

WDM6-MN3
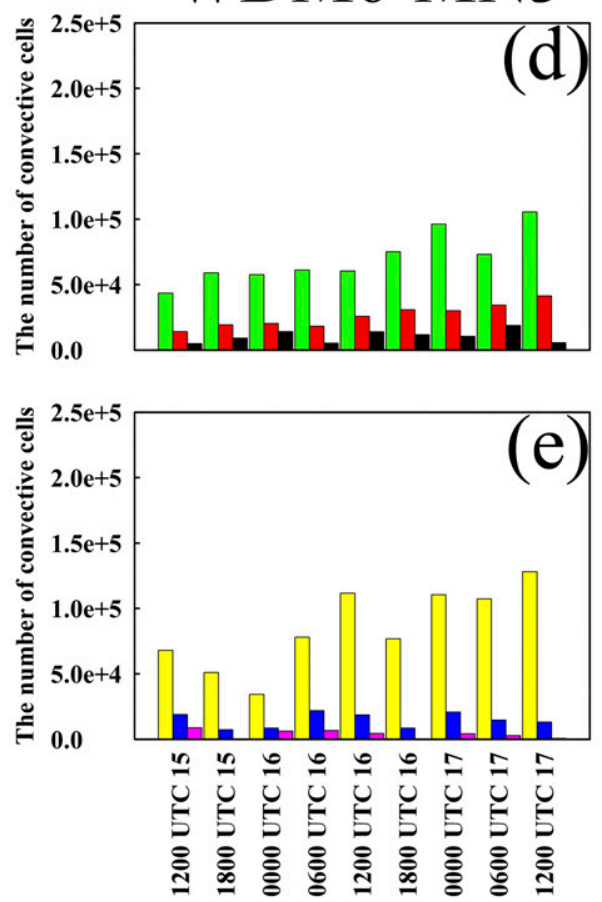

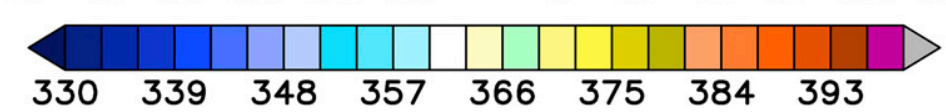

FIG. 14. The number of convective cells and Hovmöller diagram of the equivalent potential temperature (K) between (a)-(c) WSM6-MN3 and (d)-(f) WDM6-MN3. The convective cells are approximately computed with between 1.8- and 14.8-km model heights and within 60-km radius denoted as "inner" and from 60- to 120 -km radius denoted as "outer." The black horizontal line indicates the onset of RI based on the best track. 
convective cells outside the RMW are likely associated with low equivalent potential temperature or vorticity environment, such conditions are less favorable for TC intensification. Rogers et al. (2013) also showed that an intensifying TC has more convective cells inside the RMW than that of a steady-state TC. Therefore, these convective cells at each vertex of polygonal eyewalls can efficiently transport the AAM, hydrometeors, PV, and surface heat fluxes from the lower troposphere to the upper troposphere.

Figure 14 shows the number of convective cells analyzed in the inner-core region (within $60 \mathrm{~km}$ ) and outer region $(60<r \leq 120 \mathrm{~km})$ and a Hovmöller diagram of equivalent potential temperature in WSM6-MN3 and WDM6-MN3. After the onset of RI, within the innercore region, WSM6-MN3 shows a greater increase in moderate convection and CBs than WDM6-MN3 (Figs. 14a,d). For the outer region, WDM6-MN3 exhibits slightly more moderate convection and CBs than WSM6-MN3 during the RI period (Figs. 14b,e). This result is consistent with those of previous studies mentioned in the introduction that RI storms have a high concentration of CBs inside the RMW. In WDM6-MN3, the strong downdrafts produced near 4-km altitude prior to the onset of RI may play a role in suppressing the initial development of convective cells (Fig. 7d). Consequently, this large difference in the number of convective cells, particularly in the inner-core region, impacts the development of a warm core in the upper troposphere (Figs. 14c,f). During the RI period, the averaged percentage of convective cells in the inner-core region of WSM6-MN3 is larger than that of WDM6-MN3, the difference being $7.32 \%$ in terms of weak convection, $17.98 \%$ in moderate convection, and $10.80 \%$ in CBs. After the onset of RI, the significant increase in the number of convective cells within the inner-core region contributes to the formation of warm-core structure in the upper troposphere. In particular, there is a large increase in weak convection in the middle of the RI period. After this time, CBs within the inner-core region tend to slightly decrease. However, these strong convective cells present from the onset of RI to the middle of RI facilitate the development and maintenance of large cumulonimbus and cirrus clouds in the upper troposphere. These clouds are enhanced at night because of the influence of the diurnal cycle and can act as the shield in the upper troposphere, thereby contributing largely to TC intensification by destabilization (Elsberry and Park 2017). Although RI is defined by the 24-h intensification rate, the entire RI process can be divided into the following three periods relative to the development of the convective cells: first, the vertical-eyewall alignment structure by moderate convection and CBs; second, the development of a warm-core structure contributed by all convective cells; and last, the maintenance of the robust vertically aligned eyewall structure and warmcore structure by all convective cells.

To investigate the contribution of convective cells to the warm-core development during the RI, the isentropic streamfunction proposed by Pauluis and Mrowiec (2013) is used. Equation (5) indicates the isentropic distribution of the vertical mass flux:

$$
\Psi\left(z, \theta_{e}\right)=\int_{-\infty}^{\theta_{e \max }}\langle\rho w\rangle\left(z, \theta_{e}^{\prime}\right) d \theta_{e}^{\prime} .
$$

The upper limit of the integral $\theta_{e_{-} \max }$ is the maximum equivalent potential temperature within $60-\mathrm{km}$ radius and below $16-\mathrm{km}$ altitude during the RI period. Since $\theta_{e}^{\prime}=\theta_{e}-\theta_{e_{-} \max }, \theta_{e}^{\prime}$ always has negative sign, while the vertical velocity in the convective cells always has positive sign. Therefore, the sign of the accumulated isentropic streamfunction is always negative, indicating upward transport of equivalent potential temperature by convective cells at each altitude. Figure 15 shows the accumulated isentropic streamfunction at the location of different convective cells during the RI period. Compared to WDM6-MN3, greater transport of equivalent potential temperature is observed in WSM6-MN3 probably because of the number of convective cells within the inner-core region (Figs. 14a, 15a-c). During the RI period, the moderate convection and CBs in WSM6-MN3 contribute to the transport of the equivalent potential temperature more than those in WDM6-MN3. In particular, the vertical mass flux by moderate convection tends to be concentrated between the lower and midtroposphere, while that of CBs tends to be concentrated in the upper troposphere (Figs. 15b,c,e,f). Although the vertical mass flux in WDM6MN3 is smaller than in WSM6-MN3, the tendencies look similar in both cases. As a result, after the onset of RI, these differences can lead to different intensification rates. In conclusion, the increasing numbers of convective cells within the inner-core region are an important precursor for TC intensification as well as for the vertical alignment of the eyewall structure and warm-core development.

\section{Discussion}

Previous studies have emphasized that CBs within the RMW create favorable conditions for RI (Rogers 2010; Rogers et al. 2013, 2015; Miyamoto and Takemi 2015). CBs tend to be enhanced in the downshear area of TCs, while they are prone to collapse in the upshear area due to large subsidence (Chen and Gopalakrishnan 2015). Through this discussion, we elaborate on how deep 


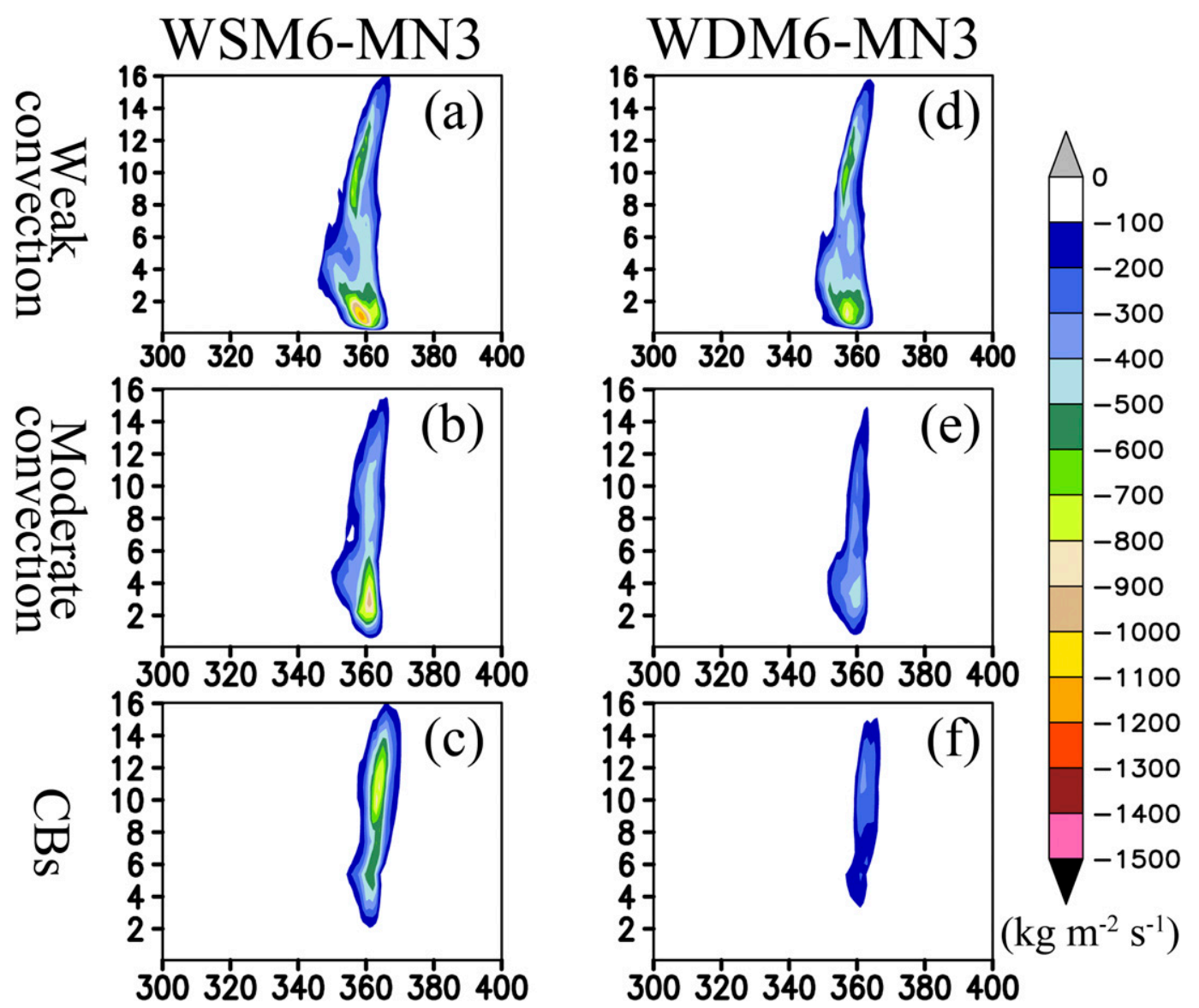

FIG. 15. The accumulated isentropic streamfunction $\Psi\left(z, \theta_{e}\right)$ within $60-\mathrm{km}$ radius throughout the RI period with the convective cells in conditions of (a),(d) weak convection; (b),(e) moderate convection; and (c),(f) CBs. The ordinate and abscissa indicate the altitude (km) and equivalent potential temperature $(\mathrm{K})$.

convective cells can develop in the downshear of TCs, and how the vertical alignment of the eyewall can be achieved during the RI period. For this detailed analysis, only the results of WSM6-MN3 are used.

Figures 16 and 17 show the cross section of the polygonal eyewall structure and skew $T-\log p$ diagrams in the following four quadrants: downshear left (DSL), downshear right (DSR), upshear left (USL), and upshear right (USR) as shown in Fig. 13e. In the USR quadrant between the boundary layer and midtroposphere (Fig. 16d), initial convective cells seem to be triggered by supergradient winds, which can generate overshooting flows against the radial inflow (Gray and Shea 1973; Green and Zhang 2015). However, large subsidence is apparent in the upper troposphere (Fig. 17d). Subsequently, the updrafts develop further as they move into the DSR area (Fig. 16b). In the DSR quadrant, the profiles for both the dewpoint temperature and temperature show that the air column is completely saturated from near the surface to about $500 \mathrm{hPa}$ (Fig. 17b). Meanwhile, in the DSL quadrant (Fig. 16a), deep convective cells between 700 and $200 \mathrm{hPa}$ exhibit a completely saturated profile (Fig. 17a). These deep convective cells can greatly contribute to the vertical alignment and development of the warm core in TCs. In addition, compared to other quadrants, deep radial flows between the lower and upper troposphere are also observed (Fig. 16a). These deep inflow layers facilitate the alignment of deep convective cells when they move in opposite direction to the vertical wind shear. Once the deep convective cells have developed, as seen in Fig. 16a, they may release substantial latent heat above the freezing level, as discussed in Kelley and Halverson (2011). In addition, the rapid transport of surface heat fluxes, AAM, absolute vorticity, PV, and hydrometeors from the lower to upper troposphere can be found. However, these deep convective cells tend to collapse and tilt outwards in the USL quadrant because of 

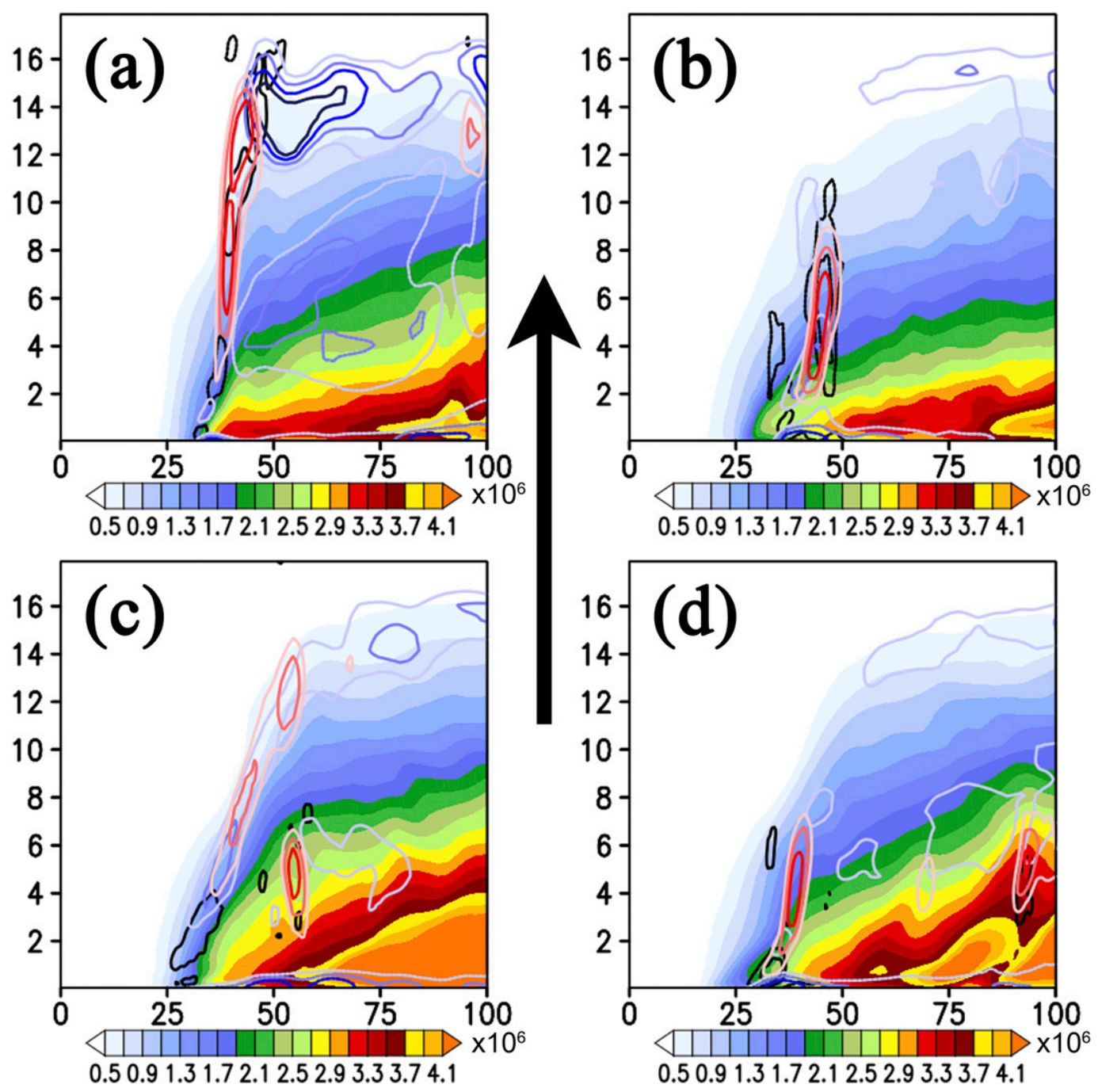

FIG. 16. Cross sections of Fig. 13e in four quadrants: (a) DSL, (b) DSR, (c) USL, and (d) USR. The thick black arrow indicates the direction of VWS. The black, red, and blue contours indicate the net radial force, vertical velocity, and radial wind, respectively. The shaded area represents the AAM $\left(\mathrm{kg} \mathrm{m}^{-1} \mathrm{~s}^{-1}\right)$. The wind speed is normalized by the radial maximum value, (a) $w: 11.64 \mathrm{~m} \mathrm{~s}^{-1}$ and $v_{r}:-20.88 \mathrm{~m} \mathrm{~s}^{-1}$, (b) $w: 8.68 \mathrm{~m} \mathrm{~s}^{-1}$ and $v_{r}:-37.62 \mathrm{~m} \mathrm{~s}^{-1}$, (c) $w: 7.76 \mathrm{~m} \mathrm{~s}^{-1}$ and $v_{r}:-21.29 \mathrm{~m} \mathrm{~s}^{-1}$, and (d) $w: 7.69 \mathrm{~m} \mathrm{~s}^{-1}$ and $v_{r}:-30.28 \mathrm{~m} \mathrm{~s}^{-1}$.

the large subsidence (Figs. 16c, 17c). These characteristics of convective cells in different quadrants are consistent with Chen and Gopalakrishnan (2015).

As a second point of discussion, we have examined how the vertical alignment of the eyewall can occur during the RI period. As detailed in the appendix, we have derived the mean AAM budget equation from the governing equation for the tangential wind. After the onset of RI, the mean radial flux (MRF) of the absolute vorticity and mean vertical advection (MVA) of AAM significantly increase (see Fig. A1). Because the MRF of the absolute vorticity can contribute to an increase in the tangential wind and MVA of AAM can indicate the vertical alignment of the AAM structure, these two terms can be used to explain the intensification and vertical alignment of TCs. The MRF of absolute vorticity and MVA of AAM are greater in WSM6-MN3 than in WDM6-MN3 during the RI period (Fig. A1). This is probably associated with the number of convective cells and convergence related to the polygonal eyewall within the inner-core region. In other words, the persistent polygonal eyewall and increasing number of convective cells can greatly contribute to the transport of MRF of absolute vorticity and MVA of AAM. Munsell et al. (2017) also stated that the convective strength allows the precession and alignment of vortex structure.

Figure 18 shows a schematic illustration of how a polygonal eyewall in the lower troposphere can contribute to 

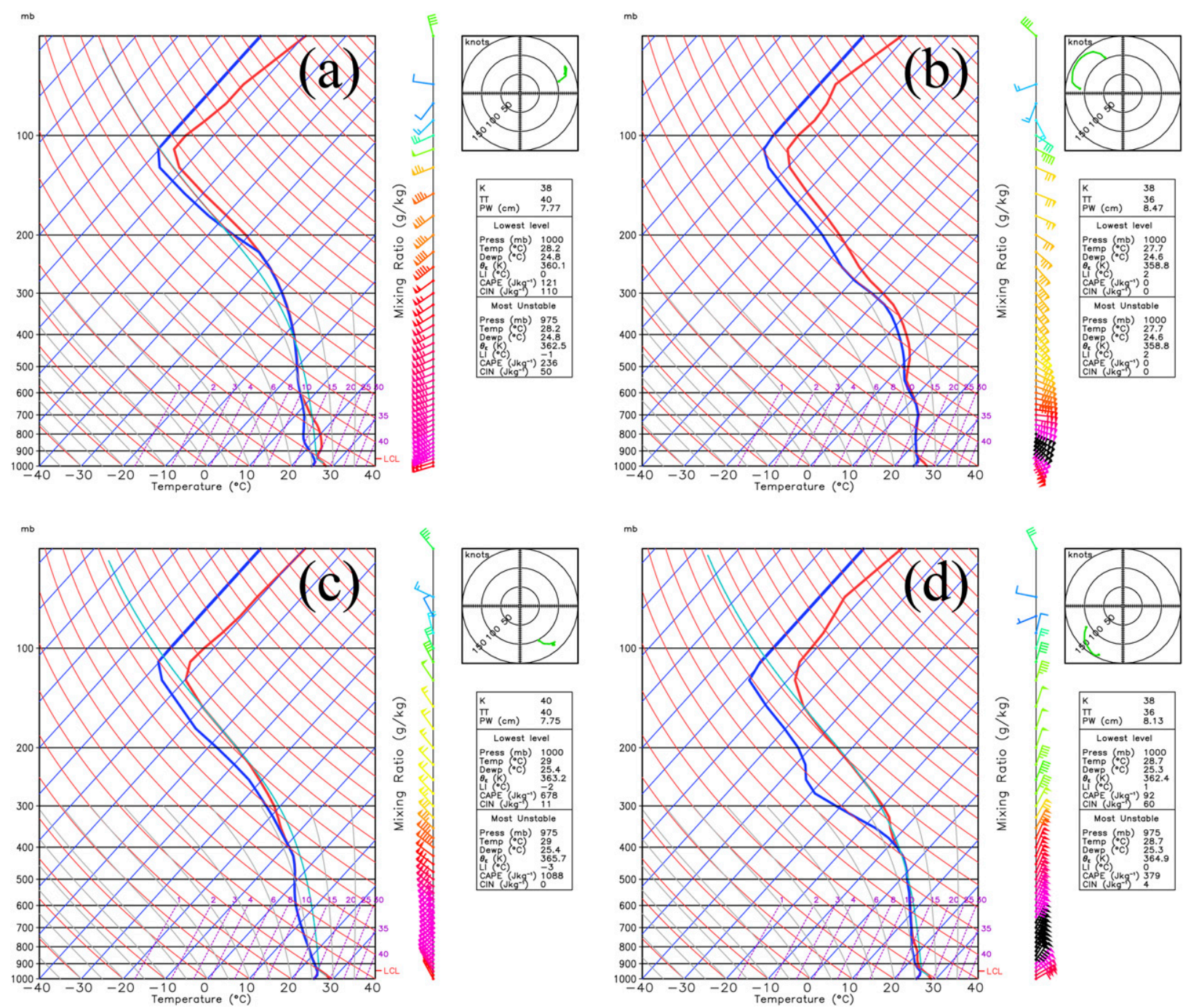

FIG. 17. As in Fig. 16, but for the skew $T-\log p$ diagrams of the CB central area in each quadrant. On the DSR side, because of the failure of LCL calculation, CAPE and CIN could not be derived. Large CAPE is generally found in upshear quadrants: (a) $236 \mathrm{~J} \mathrm{~kg}^{-1}$, (b) not computed, (c) $1088 \mathrm{~J} \mathrm{~kg}^{-1}$, and (d) $379 \mathrm{~J} \mathrm{~kg}^{-1}$. On the USR side, the large subsidence is well observed above $400 \mathrm{hPa}$. The black wind barb indicates the strongest horizontal wind speed.

RI based on these results. At each vertex of the polygonal eyewall, large radial AAM advection, high surface heat fluxes, strong horizontal wind, and energetic convection are observed. In this environment, deep convective cells shown in Fig. 16a can transport surface heat, AAM, hydrometeors, inertial stability, and absolute vorticity from the lower to upper troposphere, as well as producing cumulonimbus anvil clouds in the upper troposphere. These deep convective cells in the inner eyewall can also release significant amounts of latent heat. In addition, although the decrease of VWS primarily depends on the largescale environment, the outflow produced by these energetic convective cells can contribute locally to the reduction of VWS.

\section{Summary and conclusions}

This study has examined a possible RI mechanism associated with Typhoon Megi in 2010. To improve numerical simulations of Megi, we have developed a DI method to initialize a coarse vortex in the global domain. After a 12-cycle run, TC intensity comparable to the JMA best track is obtained as measured by the minimum sea level pressure and maximum surface wind. Based on this initialized vortex, sensitivity experiments show that intensity forecasts are more sensitive to the microphysics and PBL schemes than the track forecast. In particular, compared to the WSM6 microphysics scheme, experiments with the WDM6 microphysics scheme tend to underestimate TC intensity because of 


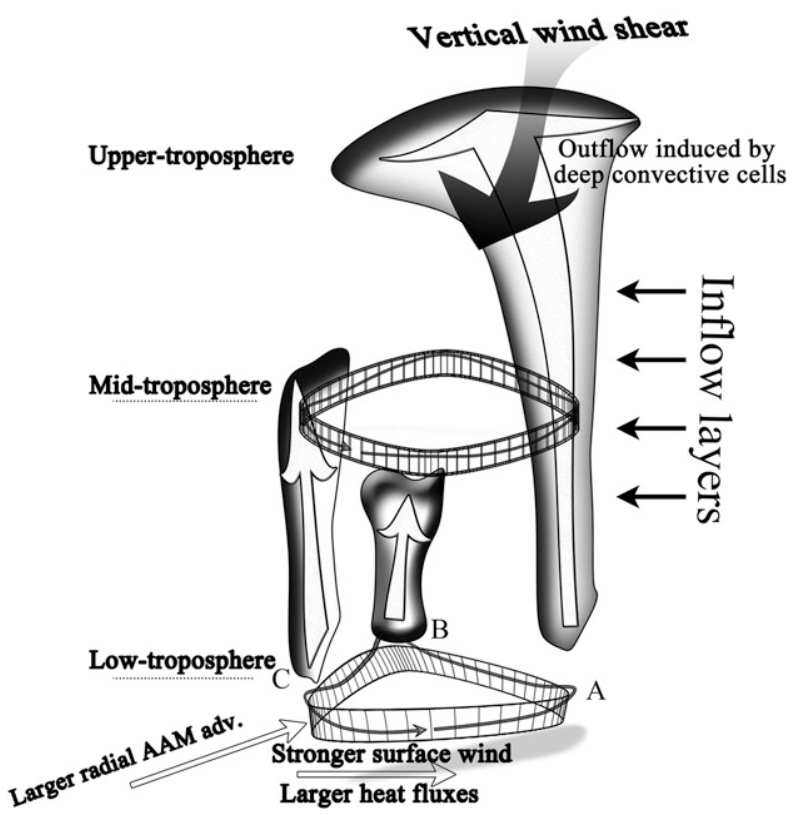

FIG. 18. A schematic illustration of the possible RI mechanism in the polygonal eyewall structure. At each vertex of polygonal eyewalls denoted by capital letters $\mathrm{A}-\mathrm{C}$, stronger surface wind and convection, larger radial AAM advection, and surface heat fluxes are well observed. Based on the present results, the strongest supergradient wind is found around $\mathrm{B}$. This schematic illustration can be compared with Houze (2010, their Fig. 24).

relatively dry environment in the lower troposphere. This dry environment in the lower troposphere is likely caused by the large mixing ratio of rainwater around 4-km altitude and the double-moment microphysical process for warm rain. As a result, based on the accepted definition of RI, with the exception of the MYJ PBL experiments, all WDM6 experiments belong to the non-RI group. In particular, since there is a considerable difference in intensity between WSM6-MN3 and WDM6-MN3 after the onset of RI, we have studied the RI mechanism through comparison of the two experiments.

Before the onset of RI, WDM6-MN3 exhibits strong downdrafts in the lower troposphere. This may suppress initial convective cells from the lower troposphere. Meanwhile, during the RI period, although both experiments have a polygonal eyewall structure within RMW, they have different maximum values of PV, radial AAM advection, surface heat fluxes, horizontal and vertical velocities, inertial stability, and gradient wind at each vertex of polygonal eyewalls. In particular, PV thickness and the number of convective cells are clearly different in both experiments inside the inner-core region. In addition, when the polygonal eyewall in the lower troposphere has a persistent wavenumber- 3 or -4 structure, more convective cells seem to exist inside the inner-core region. Furthermore, a large contribution to the vertical mass flux of equivalent potential temperature by the convective cells is observed in WSM6-MN3 during the RI period. Consequently, the difference in the number of convective cells greatly affects both the development of the warm-core structure in the upper troposphere and the vertical alignment of eyewall structure. After the end of RI, these convective cells support a robust eyewall structure until landfall. We believe that in the lower troposphere and within the RMW, a closed and persistent polygonal eyewall structure could be an important factor in RI, because such eyewalls enhance convective cells at each vertex region. To improve the reliability of these results, we plan to further explore the impact of polygonal eyewalls on RI with more case studies.

Acknowledgments. This work is supported by the Ministry of Science and Technology of Taiwan under Grant MOST 106-2111-M-002-013-MY3 and by the Office of Naval Research through Grant N62909-16-12169. We also thank the Numerical Weather Prediction and Dynamic Meteorology Laboratory of Pukyong National University for providing the Laboratory's highorder filter subroutines in this study. Helpful remarks for Yi-Hsuan Huang, Anna Vaughan, and all three anonymous reviewers are greatly appreciated.

\section{APPENDIX}

\section{Mean AAM Budget Equation}

Beginning with the governing equation for the tangential direction, the mean AAM budget equation can be derived as follows:

$$
\begin{aligned}
\frac{\partial v_{\theta}}{\partial t}= & -v_{r} \frac{\partial r v_{\theta}}{r \partial r}-v_{\theta} \frac{\partial v_{\theta}}{r \partial \theta}-w \frac{\partial v_{\theta}}{\partial z} \\
& -\left(f+\frac{v_{\theta}}{r}\right) v_{r}-\frac{1}{\rho r} \frac{\partial p}{\partial \theta}+F_{\theta},
\end{aligned}
$$

where $\left(\partial r v_{\theta} / r \partial r+v_{\theta} / r+f\right)=\zeta_{a}$, and $v_{r}$ and $F_{\theta}$ indicate the radial wind and tangential friction components. Here, air density is taken to be constant, with a value obtained by averaging the values obtained within $100-\mathrm{km}$ radius from TC center and up to $12-\mathrm{km}$ model height, that is, $0.7680 \mathrm{~kg} \mathrm{~m}^{-3}$. Equation (A1) can be simplified as (A2) by multiplying (A1) by $r$, decomposing the field into mean and disturbance components, and taking the azimuthal mean as the following:

$\rho\left[\frac{\partial r \overline{v_{\theta}}}{\partial t}=-r\left(\overline{v_{r}} \overline{\zeta_{a}}\right)-r\left(\overline{v_{r}^{\prime} \zeta_{a}^{\prime}}\right)-\bar{w} \frac{\partial r \overline{v_{\theta}}}{\partial z}-\overline{w^{\prime} \frac{\partial r v_{\theta}^{\prime}}{\partial z}}+r F_{\theta}\right]$ 

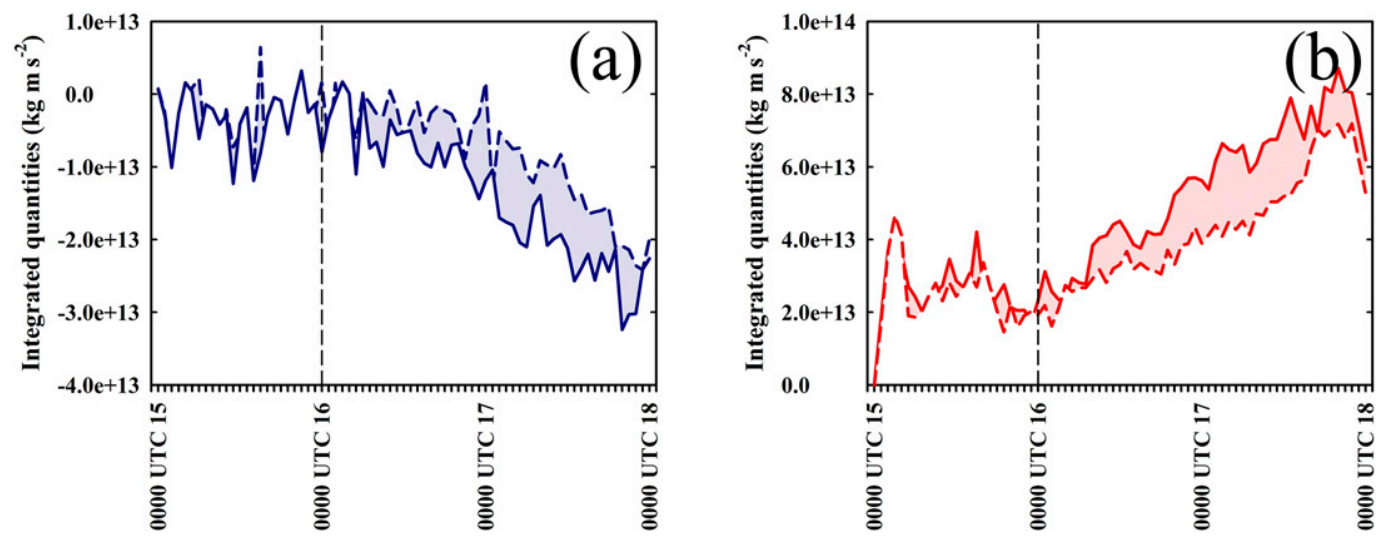

FIG. A1. The integrated quantities $\left(\mathrm{kg} \mathrm{m} \mathrm{s}^{-2}\right)$ from the center to $100-\mathrm{km}$ radius and from $50-\mathrm{m}$ to $12.1-\mathrm{km}$ model heights with relation to (a) MRF of absolute vorticity (dark blue) and (b) MVA of AAM (red). The solid and dashed lines indicate WSM6-MN3 and WDM6-MN3, respectively. The onset of RI is indicated by a black dashed line.

However, since $\partial M / \partial t=\partial / \partial t\left[(1 / 2) f r^{2}+r v_{\theta}\right]$, the equation could be approximated as $\partial M / \partial t \approx(\partial / \partial t)\left(r v_{\theta}\right)$ if the second term is much larger than the first term on the right-hand side or the time tendency of the Coriolis force is negligible within a short time period. As a result, the mean AAM local time tendency can be represented by (A3) as follows:

$$
\begin{aligned}
\rho[\partial \bar{M} / \partial t= & -r\left(\overline{v_{r}} \overline{\zeta_{a}}\right)-r\left(\overline{v_{r}^{\prime} \zeta_{a}^{\prime}}\right)-\bar{w} \partial \bar{M} / \partial z \\
& \left.-\overline{w^{\prime} \frac{\partial M^{\prime}}{\partial z}}+r F_{\theta}\right] .
\end{aligned}
$$

On the left-hand side, it shows the time tendency of the mean AAM. Meanwhile, on the right-hand side, the terms in turn represent the MRF and eddy radial flux (ERF) of the absolute vorticity, the MVA and eddy vertical advection (EVA) of AAM, and the tangential friction component, respectively. In this calculation, the eddy terms are much smaller than the mean terms (not shown). Figure A1 shows the integrated MVA and MRF from the center to 100-km radius and from $50-\mathrm{m}$ to $12.1-\mathrm{km}$ model height for WSM6-MN3 and WDM6-MN3. During the RI period, the MVA and MRF in WSM6-MN3 are larger than that of WDM6-MN3. Because MVA represents the vertical advection of AAM, it can explain the vertical alignment of the eyewall (Fig. A1b). MRF can be used to interpret the enhancement of the tangential winds by transporting absolute vorticity into the inner eyewall region (Fig. A1a). If MRF encounters deep convective cells within the inner eyewall, it may greatly enhance horizontal winds in the mid- and upper troposphere. Overall, given that the MVA and MRF is smaller in WDM6-MN3 than in WSM6-MN3, WDM6-MN3 has weaker TC intensity than that of
WSM6-MN3 in TC development. Consequently, these processes could be considered as a positive internal process of TC intensification.

\section{REFERENCES}

Andreas, E. L., 2011: Fallacies of the enthalpy transfer coefficient over the ocean in high winds. J. Atmos. Sci., 68, 1435-1445, https://doi.org/10.1175/2011JAS3714.1.

Barnes, G. M., and P. Fuentes, 2010: Eye excess energy and the rapid intensification of Hurricane Lili (2002). Mon. Wea. Rev., 138, 1446-1458, https://doi.org/10.1175/2009MWR3145.1.

Cha, D.-H., and Y. Wang, 2013: A dynamical initialization scheme for real-time forecasts of tropical cyclones using the WRF model. Mon. Wea. Rev., 141, 964-986, https://doi.org/10.1175/ MWR-D-12-00077.1.

Chang, C.-C., and C.-C. Wu, 2017: On the processes leading to the rapid intensification of Typhoon Megi (2010). J. Atmos. Sci., 74, 1169-1200, https://doi.org/10.1175/JAS-D-16-0075.1.

Chen, H., and D.-L. Zhang, 2013: On the rapid intensification of Hurricane Wilma (2005). Part II: Convective bursts and the upper-level warm core. J. Atmos. Sci., 70, 146-162, https:// doi.org/10.1175/JAS-D-12-062.1.

_ - and S. G. Gopalakrishnan, 2015: A study on the asymmetric rapid intensification of Hurricane Earl (2010) using the HWRF system. J. Atmos. Sci., 72, 531-550, https://doi.org/ 10.1175/JAS-D-14-0097.1.

Cheong, H.-B., I.-H. Kwon, and T.-Y. Goo, 2004: Further study on the high-order double-Fourier-series spectral filtering on a sphere. J. Comput. Phys., 193, 180-197, https://doi.org/10.1016/ j.jcp.2003.07.029.

_ - H.-J. Kong, H.-G. Kang, and J.-D. Lee, 2015: Fourier finiteelement method with linear basis functions on a sphere: Application to elliptic and transport equations. Mon. Wea. Rev., 143, 1275-1294, https://doi.org/10.1175/MWR-D-14-00093.1.

D'Asaro, E. A., and Coauthors, 2014: Impact of typhoons on the ocean in the Pacific. Bull. Amer. Meteor. Soc., 95, 1405-1418, https://doi.org/10.1175/BAMS-D-12-00104.1.

DeMaria, M., C. R. Sampson, J. A. Knaff, and K. D. Musgrave, 2014: Is tropical cyclone intensity guidance improving? Bull. 
Amer. Meteor. Soc., 95, 387-398, https://doi.org/10.1175/ BAMS-D-12-00240.1.

Donelan, M. A., B. K. Haus, N. Reul, W. J. Plant, M. Stiassnie, H. C. Graber, O. B. Brown, and E. S. Saltzman, 2004: On the limiting aerodynamic roughness of the ocean in very strong winds. Geophys. Res. Lett., 31, L18306, https://doi.org/10.1029/ 2004GL019460.

Elsberry, R. L., and M.-S. Park, 2017: Comments on "Multiscale structure and evolution of Hurricane Earl (2010) during rapid intensification." Mon. Wea. Rev., 145, 1565-1571, https:// doi.org/10.1175/MWR-D-16-0301.1.

Emanuel, K. A., 1986: An air-sea interaction theory for tropical cyclones. Part I: Steady-state maintenance. J. Atmos. Sci., 43, 585-604, https://doi.org/10.1175/1520-0469(1986)043<0585: AASITF $>2.0 . \mathrm{CO} ; 2$.

_ _ 1995: Sensitivity of tropical cyclones to surface exchange coefficients and a revised steady-state model incorporating eye dynamics. J. Atmos. Sci., 52, 3969-3976, https://doi.org/ 10.1175/1520-0469(1995)052<3969:SOTCTS > 2.0.CO;2.

Fovell, R. G., K. L. Corbosiero, and H.-C. Kuo, 2009: Cloud microphysics impact on hurricane track as revealed in idealized experiments. J. Atmos. Sci., 66, 1764-1778, https://doi.org/ 10.1175/2008JAS2874.1.

—, Y. P. Bu, K. L. Corbosiero, W.-W. Tung, Y. Cao, H.-C. Kuo, L.-H. Hsu, and H. Su, 2016: Influence of cloud microphysics and radiation on tropical cyclone structure and motion. $\mathrm{Mul}$ tiscale Convection-Coupled Systems in the Tropics: A Tribute to Dr. Michio Yanai, Meteor. Monogr., No. 56, Amer. Meteor. Soc., https://doi.org/10.1175/AMSMONOGRAPHS-D-15-0006.1.

Goerss, J. S., C. R. Sampson, and J. M. Gross, 2004: A history of western North Pacific tropical cyclone track forecast skill. Wea. Forecasting, 19, 633-638, https://doi.org/10.1175/1520-0434(2004) 019<0633:AHOWNP>2.0.CO;2.

Gray, W. M., and D. J. Shea, 1973: The hurricane's inner core region. II. Thermal stability and dynamic characteristics. J. Atmos. Sci., 30, 1565-1576, https://doi.org/10.1175/1520-0469(1973) 030<1565:THICRI $>2.0$. CO;2.

Green, B. W., and F. Zhang, 2013: Impacts of air-sea flux parameterizations on the intensity and structure of tropical cyclones. Mon. Wea. Rev., 141, 2308-2324, https://doi.org/10.1175/ MWR-D-12-00274.1.

_ and - 2015: Idealized large-eddy simulations of a tropical cyclone-like boundary layer. J. Atmos. Sci., 72, 1743-1764, https://doi.org/10.1175/JAS-D-14-0244.1.

Hendricks, E. A., B. D. McNoldy, and W. H. Schubert, 2012: Observed inner-core structural variability in Hurricane Dolly (2008). Mon. Wea. Rev., 140, 4066-4077, https://doi.org/10.1175/ MWR-D-12-00018.1.

- W. H. Schubert, Y.-H. Chen, H.-C. Kuo, and M. S. Peng, 2014: Hurricane eyewall evolution in a forced shallow-water model. J. Atmos. Sci., 71, 1623-1643, https://doi.org/10.1175/ JAS-D-13-0303.1.

Hodyss, D., and D. S. Nolan, 2007: Linear anelastic equations for atmospheric vortices. J. Atmos. Sci., 64, 2947-2959, https:// doi.org/10.1175/JAS3991.1.

Holliday, C. R., and A. H. Thompson, 1979: Climatological characteristics of rapidly intensifying typhoons. Mon. Wea. Rev., 107, 1022-1034, https://doi.org/10.1175/1520-0493(1979)107<1022 CCORIT $>2.0 . \mathrm{CO} ; 2$.

Hong, S.-Y., and J.-O. Lim, 2006: The WRF single-moment 6-class microphysics scheme (WSM6). J. Korean Meteor. Soc., 42, 129-151.

_- Y. Noh, and J. Dudhia, 2006: A new vertical diffusion package with an explicit treatment of entrainment processes.
Mon. Wea. Rev., 134, 2318-2341, https://doi.org/10.1175/ MWR3199.1.

$\longrightarrow$, K.-S. S. Lim, Y.-H. Lee, J.-C. Ha, H.-W. Kim, S.-J. Ham, and J. Dudhia, 2010: Evaluation of the WRF double-moment 6-class microphysics scheme for precipitating convection. Adv. Meteor., 2010, 707253, https://doi.org/10.1155/2010/707253.

Houze, R. A., Jr., 2010: Clouds in tropical cyclones. Mon. Wea. Rev., 138, 293-344, https://doi.org/10.1175/2009MWR2989.1.

Iacono, M. J., J. S. Delamere, E. J. Mlawer, M. W. Shephard, S. A. Clough, and W. D. Collins, 2008: Radiative forcing by longlived greenhouse gases: Calculations with the AER radiative transfer models. J. Geophys. Res., 113, D13103, https://doi.org/ 10.1029/2008JD009944

Janjić, Z. I., 1994: The step-mountain eta coordinate model: Further developments of the convection, viscous sublayer, and turbulence closure schemes. Mon. Wea. Rev., 122, 927-945, https://doi.org/10.1175/1520-0493(1994)122<0927:TSMECM> 2.0.CO;2.

Jiménez, P. A., J. Dudhia, J. F. González-Rouco, J. Navarro, J. P. Montávez, and E. García-Bustamante, 2012: A revised scheme for the WRF surface layer formulation. Mon. Wea. Rev., 140, 898-918, https://doi.org/10.1175/MWR-D-11-00056.1.

Kain, J. S., 2004: The Kain-Fritsch convective parameterization: An update. J. Appl. Meteor., 43, 170-181, https://doi.org/ 10.1175/1520-0450(2004)043<0170:TKCPAU > 2.0.CO;2.

Kaplan, J., and M. DeMaria, 2003: Large-scale characteristics of rapidly intensifying tropical cyclones in the North Atlantic basin. Wea. Forecasting, 18, 1093-1108, https://doi.org/10.1175/ 1520-0434(2003)018<1093:LCORIT>2.0.CO;2; Corrigendum, 19, 482, https://doi.org/10.1175/1520-0434(2004)019<0482: $\mathrm{C}>2.0 . \mathrm{CO} ; 2$

, — - and J. A. Knaff, 2010: A revised tropical cyclone rapid intensification index for the Atlantic and eastern North Pacific basins. Wea. Forecasting, 25, 220-241, https://doi.org/10.1175/ 2009WAF2222280.1.

Kelley, O. A., and J. B. Halverson, 2011: How much tropical cyclone intensification can result from the energy released inside of a convective burst? J. Geophys. Res., 116, D20118, https:// doi.org/10.1029/2011JD015954.

Kepert, J., 2001: The dynamics of boundary layer jets within the tropical cyclone core. Part I: Linear theory. J. Atmos. Sci., 58, 2469-2484, https://doi.org/10.1175/1520-0469(2001)058<2469: TDOBLJ $>2.0 . \mathrm{CO} ; 2$.

, and Y. Wang, 2001: The dynamics of boundary layer jets within the tropical cyclone core. Part II: Nonlinear enhancement. J. Atmos. Sci., 58, 2485-2501, https://doi.org/10.1175/ 1520-0469(2001)058<2485:TDOBLJ $>2.0$.CO;2.

Kieper, M. E., and H. Jiang, 2012: Predicting tropical cyclone rapid intensification using the $37 \mathrm{GHz}$ ring pattern identified from passive microwave measurements. Geophys. Res. Lett., 39, L13804, https://doi.org/10.1029/2012GL052115.

Knapp, K. R., and M. C. Kruk, 2010: Quantifying interagency differences in tropical cyclone best-track wind speed estimates. Mon. Wea. Rev., 138, 1459-1473, https://doi.org/ 10.1175/2009MWR3123.1.

Kossin, J. P., and W. H. Schubert, 2001: Mesovortices, polygonal flow patterns, and rapid pressure falls in hurricane-like vortices. J. Atmos. Sci., 58, 2196-2209, https://doi.org/10.1175/ 1520-0469(2001)058<2196:MPFPAR > 2.0.CO;2.

Kurihara, Y., M. A. Bender, and R. J. Ross, 1993: An initialization scheme of hurricane models by vortex specification. Mon. Wea. Rev., 121, 2030-2045, https://doi.org/10.1175/1520-0493 (1993)121<2030:AISOHM>2.0.CO;2. 
Kwon, I.-H., and H.-B. Cheong, 2010: Tropical cyclone initialization with a spherical high-order filter and an idealized threedimensional bogus vortex. Mon. Wea. Rev., 138, 1344-1367, https://doi.org/10.1175/2009MWR2943.1.

Lee, C.-Y., M. K. Tippett, A. H. Sobel, and S. J. Camargo, 2016: Rapid intensification and the bimodal distribution of tropical cyclone intensity. Nat. Commun., 7, 10625, https://doi.org/ 10.1038/ncomms10625.

Lewis, B. M., and H. F. Hawkins, 1982: Polygonal eye walls and rainbands in hurricanes. Bull. Amer. Meteor. Soc., 63, 1294-1301, https://doi.org/10.1175/1520-0477(1982)063<1294:PEWARI> 2.0.CO;2.

Li, T., X. Ge, M. Peng, and W. Wang, 2012: Dependence of tropical cyclone intensification on the Coriolis parameter. Trop. Cyclone Res. Rev., 1, 242-253, https://doi.org/10.6057/2012TCRR02.04.

Lim, K.-S. S., and S.-Y. Hong, 2010: Development of an effective double-moment cloud microphysics scheme with prognostic cloud condensation nuclei $(\mathrm{CCN})$ for weather and climate models. Mon. Wea. Rev., 138, 1587-1612, https://doi.org/ 10.1175/2009MWR2968.1.

Lynch, P., 1997: The Dolph-Chebyshev window: A simple optimal filter. Mon. Wea. Rev., 125, 655-660, https://doi.org/10.1175/ 1520-0493(1997)125<0655:TDCWAS>2.0.CO;2.

— , and X.-Y. Huang, 1994: Diabatic initialization using recursive filters. Tellus, 46A, 583-597, https://doi.org/10.3402/tellusa. v46i5.15646.

McFarquhar, G. M., B. F. Jewett, M. S. Gilmore, S. W. Nesbitt, and T.-L. Hsieh, 2012: Vertical velocity and microphysical distributions related to rapid intensification in a simulation of Hurricane Dennis (2005). J. Atmos. Sci., 69, 3515-3534, https:// doi.org/10.1175/JAS-D-12-016.1.

Menelaou, K., M. K. Yau, and Y. Martinez, 2013: Impact of asymmetric dynamical processes on the structure and intensity change of two-dimensional hurricane-like annular vortices. J. Atmos. Sci., 70, 559-582, https://doi.org/10.1175/JAS-D-12-0192.1.

Miyamoto, Y., and T. Takemi, 2015: A triggering mechanism for rapid intensification of tropical cyclones. J. Atmos. Sci., 72, 2666-2681, https://doi.org/10.1175/JAS-D-14-0193.1.

Montgomery, M. T., M. E. Nicholls, T. A. Cram, and A. B. Saunders, 2006: A vortical hot tower route to tropical cyclogenesis. J. Atmos. Sci., 63, 355-386, https://doi.org/10.1175/ JAS3604.1.

Munsell, E. B., F. Zhang, J. A. Sippel, S. A. Braun, and Y. Weng, 2017: Dynamics and predictability of the intensification of Hurricane Edouard (2014). J. Atmos. Sci., 74, 573-595, https:// doi.org/10.1175/JAS-D-16-0018.1.

Nakanishi, M., and H. Niino, 2006: An improved Mellor-Yamada level-3 model: Its numerical stability and application to a regional prediction of advection fog. Bound.-Layer Meteor., 119, 397-407, https://doi.org/10.1007/s10546-005-9030-8.

Nolan, D. S., and L. D. Grasso, 2003: Nonhydrostatic, three dimensional perturbations to balanced, Hurricane-like vortices. Part II: Symmetric response and nonlinear simulations. J. Atmos. Sci., 60, 2717-2745, https://doi.org/10.1175/1520-0469 (2003) $060<2717$ :NTPTBH $>2.0 . C O ; 2$.

Park, J.-R., H.-B. Cheong, and H.-G. Kang, 2011: High-order spectral filter for the spherical-surface limited area. Mon. Wea. Rev., 139, 1256-1278, https://doi.org/10.1175/2010MWR3440.1.

Pauluis, O. M., and A. A. Mrowiec, 2013: Isentropic analysis of convective motions. J. Atmos. Sci., 70, 3673-3688, https:// doi.org/10.1175/JAS-D-12-0205.1.

Powell, M. D., P. J. Vickery, and T. A. Reinhold, 2003: Reduced drag coefficient for high wind speeds in tropical cyclones. Nature, 24, 395-419, https://doi.org/10.1038/ nature 01481.

Raymond, D. J., and H. Jiang, 1990: A theory for long-lived mesoscale convective systems. J. Atmos. Sci., 47, 3067-3077, https://doi.org/10.1175/1520-0469(1990)047<3067:ATFLLM> 2.0.CO;2.

Reasor, P. D., M. D. Eastin, and J. F. Gamache, 2009: Rapidly intensifying Hurricane Guillermo (1997). Part I: Lowwavenumber structure and evolution. Mon. Wea. Rev., 137, 603-631, https://doi.org/10.1175/2008MWR2487.1.

Richter, D. H., R. Bohac, and D. P. Stern, 2016: An assessment of the flux profile method for determining air-sea momentum and enthalpy fluxes from dropsonde data in tropical cyclones. J. Atmos. Sci., 73, 2665-2682, https://doi.org/10.1175/JAS-D15-0331.1.

Rogers, R., 2010: Convective-scale structure and evolution during a high-resolution simulation of tropical cyclone rapid intensification. J. Atmos. Sci., 67, 44-70, https://doi.org/10.1175/ 2009JAS3122.1.

_ P. Reasor, and S. Lorsolo, 2013: Airborne Doppler observations of the inner-core structural differences between intensifying and steady-state tropical cyclones. Mon. Wea. Rev. 141, 2970-2991, https://doi.org/10.1175/MWR-D-12-00357.1.

$\longrightarrow, \ldots$, and J. A. Zhang, 2015: Multiscale structure and evolution of Hurricane Earl (2010) during rapid intensification. Mon. Wea. Rev., 143, 536-562, https://doi.org/10.1175/MWR-D-14-00175.1.

Rozoff, C. M., J. P. Kossin, W. H. Schubert, and P. J. Mulero, 2009: Internal control of hurricane intensity variability: The dual nature of potential vorticity mixing. J. Atmos. Sci., 66, 133-147, https://doi.org/10.1175/2008JAS2717.1.

— D. S. Nolan, J. P. Kossin, F. Zhang, and J. Fang, 2012: The roles of an expanding wind field and inertial stability in tropical cyclone secondary eyewall formation. J. Atmos. Sci., 69, 2621-2643, https://doi.org/10.1175/JAS-D-11-0326.1.

Schecter, D. A., and M. T. Montgomery, 2007: Waves in a cloudy vortex. J. Atmos. Sci., 64, 314-337, https://doi.org/10.1175/ JAS3849.1.

Schubert, W. H., M. T. Montgomery, R. K. Taft, T. A. Guinn, S. R. Fulton, J. P. Kossin, and J. P. Edwards, 1999: Polygonal eyewalls, asymmetric eye contraction, and potential vorticity mixing in hurricanes. J. Atmos. Sci., 56, 1197-1223, https:// doi.org/10.1175/1520-0469(1999)056<1197:PEAECA > 2.0.CO;2.

Skamarock, W. C., and Coauthors, 2008: A description of the Advanced Research WRF version 3. NCAR Tech. Note NCAR/TN-475+STR, 113 pp., http://dx.doi.org/10.5065/ D68S4MVH.

Vigh, J. L., and W. H. Schubert, 2009: Rapid development of the tropical cyclone warm core. J. Atmos. Sci., 66, 3335-3350, https://doi.org/10.1175/2009JAS3092.1.

Wang, H., and Y. Wang, 2014: A numerical study of Typhoon Megi (2010). Part I: Rapid intensification. Mon. Wea. Rev., 142, 29-48, https://doi.org/10.1175/MWR-D-13-00070.1.

Wang, Y., 2002: Vortex Rossby waves in a numerically simulated tropical cyclone. Part II: The role in tropical cyclone structure and intensity changes. J. Atmos. Sci., 59, 1239-1262, https://doi.org/10.1175/1520-0469(2002)059<1239: VRWIAN $>2.0 . \mathrm{CO} ; 2$.

— , and C.-C. Wu, 2004: Current understanding of tropical cyclone structure and intensity changes-A review. Meteor. Atmos. Phys., 87, 257-278, https://doi.org/10.1007/s00703-003-0055-6.

Willoughby, H. E., J. A. Clos, and M. G. Shoreibah, 1982: Concentric eye walls, secondary wind maxima, and the evolution of the hurricane vortex. J. Atmos. Sci., 39, 395-411, 
https://doi.org/10.1175/1520-0469(1982)039<0395:CEWSWM > 2.0.CO;2.

Wu, C.-C., G.-Y. Lien, J.-H. Chen, and F. Zhang, 2010: Assimilation of tropical cyclone track and structure based on the ensemble Kalman filter (EnKF). J. Atmos. Sci., 67, 3806-3822, https://doi.org/10.1175/2010JAS3444.1.

—, S.-N. Wu, H.-H. Wei, and S. F. Abarca, 2016a: The role of convective heating in tropical cyclone eyewall ring evolution. J. Atmos. Sci., 73, 319-330, https://doi.org/10.1175/JAS-D-15-0085.1.

— W.-T. Tu, I.-F. Pun, I.-I. Lin, and M. S. Peng, 2016b: Tropical cyclone-ocean interaction in Typhoon Megi (2010)—A synergy study based on ITOP observations and atmosphereocean coupled model simulations. J. Geophys. Res. Atmos., 121, 153-167, https://doi.org/10.1002/2015JD024198.

Yuter, S. E., and R. A. Houze Jr., 1995: Three-dimensional kinematic and microphysical evolution of Florida cumulonimbus.
Part III: Vertical mass transport, mass divergence, and synthesis. Mon. Wea. Rev., 123, 1964-1983, https://doi.org/10.1175/ 1520-0493(1995)123<1964:TDKAME > 2.0.CO;2.

Zhang, S., T. Li, X. Ge, M. Peng, and N. Pan, 2012: A 3DVARbased dynamical initialization scheme for tropical cyclone predictions. Wea. Forecasting, 27, 473-483, https://doi.org/ 10.1175/WAF-D-10-05066.1.

Zhu, P., K. Menelaou, and Z. Zhu, 2014: Impact of subgrid-scale vertical turbulent mixing on eyewall asymmetric structures and mesovortices of hurricanes. Quart. J. Roy. Meteor. Soc., 140, 416-438, https://doi.org/10.1002/qj.2147.

Zou, X., and Q. Xiao, 2000: Studies on the initialization and simulation of a mature hurricane using a variational bogus data assimilation scheme. J. Atmos. Sci., 57, 836-860, https://doi.org/10.1175/1520-0469(2000)057<0836: SOTIAS $>2.0 . \mathrm{CO} ; 2$. 